\title{
Third-Country Effects on the Exchange Rate
}

\author{
Kimberly A. Berg \\ Nelson C. Mark \\ University of Notre Dame \\ University of Notre Dame and NBER
}

August 2012

\begin{abstract}
This paper attributes the exchange-rate disconnect puzzle, which we characterize as low $\bar{R}^{2}$ in shorthorizon predictive regressions, to omitted 'third-country' variables. Using a three-country DSGE exchange rate model, we identify channels through which shocks originating in Country 3 can generate substantial variability in the bilateral exchange rate between Countries 1 and 2. In Monte Carlo experiments, using the model as the data generating process, we find that including Country 3 variables in otherwise conventional two-country exchange-rate regressions result in sizable increases in explanatory power. Empirical analysis of data from the U.S. and eleven other countries support the predictions of the theory.
\end{abstract}

Keywords: Exchange Rates, Disconnect Puzzle, Multi-Country Model

JEL: F31, F37 


\section{Introduction}

This paper addresses the exchange-rate disconnect puzzle, a term coined by Obstfeld and Rogoff (2000) to describe the "exceedingly weak relationship (except, perhaps, in the longer run) between the exchange rate and virtually any macroeconomic aggregates." The puzzle applies to both nominal and real exchange rates. While there are many ways to characterize the exchange-rate disconnect puzzle, in this paper, the puzzle refers to the low adjusted $R^{2}$ in regressions of future short-horizon changes in the (log) exchange rate on current macroeconomic fundamentals. For example, using quarterly data from 1999 to 2011, a regression of the one-quarter ahead depreciation in the Danish krone relative to the USD (U.S. dollar) on the current Danish-U.S. DPPP (deviation from purchasing-power parity) has an $\bar{R}^{2}=-0.003$. A similar regression of the exchange-rate depreciation on Taylor-rule fundamentals (Danish and U.S. inflation rates and output gaps) produces an $\bar{R}^{2}=-0.041$. We can agree that these regressions have very low explanatory power. ${ }^{1}$

The low $\bar{R}^{2}$ that we obtain is typical in the empirical literature on exchange rate determination. Also, as in the literature, we employ only variables of the two countries associated with the bilateral exchange rate under consideration as regressors. This seems to have become standard practice as research draws empirical guidance from exchange rate models that are typically presented in twocountry environments. But in fact, the data are generated from a multi-country world and restricting our attention to two-country models can be an important limitation. This paper shows that failure to account for third-country effects on bilateral exchange rates represents an important missing piece of the exchange-rate disconnect puzzle. ${ }^{2}$ We show theoretically and empirically that adding Country 3 variables as regressors in predictive regressions of the exchange rate between Countries 1 and 2 can lead to sizable increases in the $\bar{R}^{2}{ }^{3}$

In the theoretical work, we employ a complete markets DSGE (dynamic stochastic general equilibrium) exchange-rate model. This is a three-country extension to an otherwise conventional two-country sticky-price model that has been used to study exchange rates. Firms engage in Calvo-style local currency price setting and monetary policy is conducted through interest-rate rules that depend on expected inflation, the output gap, the lagged interest rate, and (possibly) the exchange rate. Exogenous country-wide technology and monetary policy shocks drive the dynamics. Markets are complete so the real exchange rate between Countries 1 and 2 depends on relative consumption between 1 and 2 .

\footnotetext{
${ }^{1}$ Empirical exchange rate research has intensively examined the explanatory / predictive power of monetary and purchasing-power parity fundamentals (Mark, 1995, Chinn and Meese, 1995, Cheung et al., 2005, Mark and Sul, 2001, Rapach and Wohar, 2004, Groen 2005). Other recent work has incorporated monetary policy endogeneity via interestrate feedback rules (Engel and West (2006), Mark, 2008, Molodtsova and Papell, 2009, Molodtsova et al., 2008, 2011). Although there are institutional reasons to favor the Taylor- Rule approach, Engel, Mark and West (2007) conclude that the power to beat the random walk appears to be the strongest under PPP fundamentals.

${ }^{2}$ For any bilateral exchange rate under consideration, two countries are involved. Throughout the paper, the term 'third-country' refers generically to some country beyond the two for which the bilateral exchange rate refers. We do not mean to suggest that the same 'third country' is involved in determination of all bilateral exchange rates. Different exchange rates may be affected by different third countries, or possibly by more than one such third country.

${ }^{3} \mathrm{We}$ use the predictive regression as an organizing device to talk about exchange rate disconnect, but the focus of our paper is not on exchange rate prediction per se.
} 
Hence, in order for Country 3 shocks to impact the exchange rate between 1 and 2, there must be some asymmetry between 1 and 2 so that the countries respond differently to shocks from 3 . We consider two such asymmetries.

The first of these asymmetries lies in the conduct of monetary policy. A direct channel for thirdcountry effects on the exchange rate between 1 and 2 is created when Country 2 engages in a managed float against Country 3's currency. Since 2's interest rate depends on its real exchange rate with 3, a Country 3 shock induces a divergence between 1 and 2's real interest rates and their consumption growth rates which results in exchange-rate movements between 1 and 2 . The second asymmetry that we consider is cross-country differences in the degree of price stickiness. These differences are assumed to occur by point of origin where the ability to adjust prices by firms in country $i$ is different from firms in country $j$. Under symmetric price stickiness, a favorable Country 3 technology shock induces firms in 3 to initially lower prices of exports to 1 and 2. Country 2 firms initially raise prices of domestic sales and prices of exports to 1 in response to rising demand. The introduction of asymmetric price stickiness generates an indirect channel for third-country effects on the exchange rate; a Country 3 shock now drives a wedge in inflation between 1 and 2, which then induces differences in their real interest rates and consumption, resulting in movements of the exchange rate between 1 and 2 .

Given these heterogeneities, impulse response analyses performed on parameterized versions of the model show that Country 3 shocks are quantitatively important and can have a larger impact than Country 2 shocks on the exchange rate between 1 and 2 . These results strongly suggest that thirdcountry variables may be important omitted variables. To investigate this conjecture, we conduct Monte Carlo experiments using the model as the data-generating mechanism. We compare the mean $\bar{R}^{2}$ values from 'two-country' predictive regressions (in which future short-horizon changes in the log exchange rate between 1 and 2 are regressed on macroeconomic fundamentals only of Countries 1 and 2 ) with 'third-country' regressions (that condition on the fundamentals of all three countries). We find that the adjusted $R^{2}$ from the latter can be more than twice as large as the $\bar{R}^{2}$ values from regressions that condition only on variables of Countries 1 and 2 .

We then report empirical results that support predictions of the theoretical model and our diagnosis of the disconnect puzzle. Our first piece of evidence draws from estimates of monetary policy feedback rules for eleven countries. The form of the feedback rule we estimate is as in Clarida et al. (1998) which depends on output gaps, inflation and the real exchange rate. We find evidence that ten of the eleven countries engage in de facto exchange rate management against either the euro, the Swiss franc, or the yen, which supports the direct channel for third-country effects on these countries' exchange rates with the USD.

Our second piece of empirical evidence is based on comparison of two-country and three-country short-horizon regressions of future currency depreciations relative to the USD. Our regression results using the data are generally stronger than the results from the Monte Carlo experiments using the three-country model as the data generating process. As a case in point, augmenting the regression of the 1-month ahead krone-USD exchange rate with Japanese macro fundamentals raises the $\bar{R}^{2}$ from -0.003 to 0.124 in the DPPP regression and from -0.041 to 0.177 in the Taylor-rule fundamentals 
regression.

Our paper is related to and can be thought of as providing a theory for recent empirical work by Engel et al. (2012) and Greenaway-McGrevy et al. (2012) who find that common factors are important drivers of bilateral exchange rates. In Engel et al. (2012), the exchange rates of 17 countries against the USD were found to be well described by three common factors. These three factors remain the most important source of variation, accounting for nearly two-thirds of the variation even after controlling for bilateral macro fundamentals. Our interpretation of this is that the three common factors represent third-country sources of variation. ${ }^{4}$ In other research, Greenaway-McGrevy et al. (2012), identify these three factors with observed data. They identify the dominant factor with the USD / euro exchange rate, the second factor with the USD / Swiss franc rate, and the third factor with the USD / yen rate. We draw on the Greenaway-McGrevy et al. identification in guiding our choices to serve as 'third-countries' in our empirical analysis.

The exchange rate is an important macroeconomic variable whose variation can induce large intersectoral reallocations of resources. Because of its prominent role, it has been a long-standing goal of international economists to understand its dynamic behavior. Much of the modeling research, however, has been concerned with the ability of sticky-price models to explain the volatility and persistence of real exchange rates (Chari et al., 2002, Benigno, 2004, Steinsson, 2008, Bergin, 2006, and Kollman, 2001) as well as to match international business cycle facts. Our paper has a narrower focus and is more closely related to Evans (2012) who also seeks to solve the exchange-rate disconnect puzzle. His explanation for the low $R^{2}$ in exchange rate regressions is that most of the variation in exchange rates are driven by unobserved, non-fundamental risk (taste) shocks whereas we emphasize observed fundamental factors. Our work is foreshadowed by Hodrick and Vassalou (2002), who found that multi-country models were better able to explain the dynamics of exchange rates than two-country models.

The remainder of the paper is organized as follows. The next section begins with a simple illustrative partial equilibrium model that lays out the direct third country effects on the exchange rate through monetary policy. Section 2 presents the complete three country DSGE model. The model's properties and predictions are discussed in Section 3. Section 4 presents the supporting empirical evidence and Section 5 concludes.

\section{A Channel of Third-Country Dependence through Monetary Policy}

Before discussing the full-blown three-country model, we present a simplified partial equilibrium framework that transparently delineates the direct channel of third-country influence through a policy of exchange-rate management. In this environment, Country 2 manages its exchange rate against Country 3 which causes 2's real exchange rate with 1 to depend on 2's real exchange rate with 3 . Our

\footnotetext{
${ }^{4}$ They also find that the post euro-creation period constitutes a separate regime. Because of the important role played by the euro in international finance, and to avoid complexities involved in estimation across different regimes, we limit our empirical analyses to the period since the launch of the euro.
} 
discussion here addresses determination of the real exchange rate.

Let Country 1 be the U.S., Country 2 be "home," and Country 3 be the euro area. Notation is $\hat{e}_{i, j, t}$ for the $\log$ currency $i$ price of one unit of currency $j$. The $\log$ real exchange rate between $i$ and $j$ is $\hat{q}_{i, j, t}=\hat{e}_{i, j t}+\hat{p}_{j, t}-\hat{p}_{i, t}$ where $\hat{p}_{i, t}$ is the $(\log )$ general price level of country $i$, with $\hat{e}_{i, i, t}=\hat{q}_{i, i, t}=1$, $\hat{e}_{i, j, t}=-\hat{e}_{j, i, t}$, and $\hat{q}_{i, j, t}=-\hat{q}_{j, i, t}$.

The monetary authorities in Country 1 respond to developments in expected domestic inflation and the output gap

$$
i_{1, t}=\delta+\lambda E_{t}\left(\pi_{1, t+1}\right)+\phi \tilde{y}_{1, t}+\epsilon_{1, t},
$$

where $\pi_{j, t+1}$ is the general price level inflation in country $j$ from time $t$ to $t+1, \tilde{y}_{j, t}$ is $j^{\prime} s$ output gap, and $\epsilon_{j, t}$ is a shock to $j^{\prime} s$ monetary policy. ${ }^{5}$ For simplicity, we assume constant and identical target inflation rates (which are impounded into the parameter $\delta$ ) and identical response coefficients on inflation and the output gaps.

Authorities in Country 2 pursue a managed float against the Country 3 currency and view purchasing power parity as the long-run equilibrium value of the nominal exchange rate. Exchange-rate management means that 2 adjusts its interest rate in response to variation in the log real exchange rate $\hat{q}_{2,3, t}$, between 2 and 3 according to

$$
i_{2, t}=\delta+\lambda E_{t}\left(\pi_{2, t+1}\right)+\phi \tilde{y}_{2, t}+\sigma \hat{q}_{2,3, t}+\epsilon_{2, t} .
$$

When $\hat{q}_{2,3, t}$ increases, 2 experiences a real depreciation relative to 3 . To stabilize the exchange rate, $\sigma$ should be positive. Now assume that UIP (uncovered interest parity) holds between 1 and 2,

$$
i_{1, t}-i_{2, t}=E_{t}\left(\hat{e}_{1,2, t+1}\right)-\hat{e}_{1,2, t} .
$$

From both sides of eq.(3), subtract $E_{t}\left(\pi_{1, t+1}\right)$ and add $E_{t}\left(\pi_{2, t+1}\right)$. Next, substitute the policy rules (1) and (2) for the interest rates. This gives

$$
\hat{q}_{1,2, t}=(\lambda-1)\left(E_{t} \pi_{2, t+1}-E_{t} \pi_{1, t+1}\right)+\phi\left(\tilde{y}_{2, t}-\tilde{y}_{1, t}\right)+\left(\epsilon_{2, t}-\epsilon_{1, t}\right)+\sigma \hat{q}_{2,3, t}+E_{t} \hat{q}_{1,2, t+1} .
$$

We note that $\hat{q}_{2,3, t}=\left(\hat{q}_{1,3, t}-\hat{q}_{1,2, t}\right)$, which we substitute into (4) and rearrange to obtain the stochastic difference equation

$$
\begin{aligned}
\hat{q}_{1,2, t} & =\frac{1}{(1+\sigma)}\left((\lambda-1)\left(E_{t} \pi_{2, t+1}-E_{t} \pi_{1, t+1}\right)+\phi\left(\tilde{y}_{2, t}-\tilde{y}_{1, t}\right)+\left(\epsilon_{2, t}-\epsilon_{1, t}\right)+\sigma \hat{q}_{1,3, t}\right) \\
& +\frac{1}{(1+\sigma)} E_{t} \hat{q}_{1,2, t+1} .
\end{aligned}
$$

For expository purposes, we sharpen the discussion by assuming that the inflation differential, output gap differential and real exchange rate between 1 and 3 have zero-mean first-order autoregressive representations,

$$
\left(\pi_{2, t}-\pi_{1, t}\right)=\rho_{\pi}\left(\pi_{2, t-1}-\pi_{1, t-1}\right)+u_{\pi, t},
$$

\footnotetext{
${ }^{5}$ Empirical formulations typically include the lagged policy rate to capture the central bank's desire for interest rate smoothing. Including lagged policy rates here do not change the qualitative conclusions, but makes the algebra considerably more messy.
} 


$$
\begin{gathered}
\left(\tilde{y}_{2, t}-\tilde{y}_{1, t}\right)=\rho_{y}\left(\tilde{y}_{2, t-1}-\tilde{y}_{1, t-1}\right)+u_{y, t}, \\
\hat{q}_{1,3, t}=\rho_{q} \hat{q}_{1,3, t-1}+u_{q, t} .
\end{gathered}
$$

Forward iteration of eq.(5) and use of prediction formulae implied by eqs.(6)-(8) gives the fundamentals solution of the real exchange rate between 1 and 2,

$\hat{q}_{1,2, t}=\left(\frac{\sigma}{1+\sigma-\rho_{q}}\right) \hat{q}_{1,3, t}+\left(\frac{(\lambda-1)}{1+\sigma-\rho_{\pi}}\right)\left(\pi_{2, t+k}-\pi_{1, t+k}\right)+\left(\frac{\phi}{1+\sigma-\rho_{y}}\right)\left(\tilde{y}_{2, t}-\tilde{y}_{1, t}\right)+\frac{\epsilon_{2, t}-\epsilon_{1, t}}{1+\sigma}$,

from which it is seen that $\hat{q}_{1,2, t}$ depends on $\hat{q}_{1,3, t}$. Hence, monetary policy with an exchange rate target against a "third country" currency induces a cross-rate determinant into the primary exchange rate. As a result, empirical analyses that include only Country 1 and 2 variables omit potentially important explanatory variables.

This direct exchange-rate management channel has the capacity to explain Greenaway-McGrevy et al. (2012) identification of the USD/euro exchange rate as the dominant common factor in exchange rates. If we think of a multi-country world where there are many (say $N$ ) Country 2 s, that manage their exchange rates against the euro, there will be $N$ currency exchange rates against the USD that are correlated with the USD/euro exchange rate. The USD/euro exchange rate thus becomes a common factor in this panel of 'Country 2' exchange rates against the dollar.

The specific form of the managed float is not critical for this conclusion. While we assume that the authorities react to variations in the real exchange rate, cross-rate influence will also appear if Country 2 's policy rate reacts to the change in its exchange rate with Country $3 .{ }^{6}$ Furthermore, the general result is not sensitive to the assumption that the authorities are managing relative to a single cross-rate. Exchange rate management against a basket of currencies (as done since 2005 by the central banks of Russia, China and Malaysia, see Sokolov (2012)) will produce similar qualitative results.

\section{A Three Country Exchange-Rate Model}

In this section, we develop a three-country exchange rate model to more fully investigate Country 3 effects on the exchange rate between 1 and 2. The model is a three-country extension to the twocountry New Keynesian model of Benigno (2004), who investigated if monetary policies can generate empirically consistent volatility and persistence in the exchange rate. As in the previous section, we loosely think of the U.S. as Country 1, a representative home country as Country 2 and the euro region as Country 3. There is no capital in the model and the production technology requires only labor. Each country is populated by a continuum of economic agents with population size proportional to the range of produced goods. Derivations of the model's equations are given in the appendix.

\footnotetext{
${ }^{6}$ In this case, UIP implies a second-order stochastic difference equation. The solution has the same qualitative implication that the exchange rate between 1 and 2 depends in part on the expected present value of the cross rate.
} 


\subsection{The Household's Problem}

In period $t$, any one of $N$ possible states of nature can occur. Let $s_{t}$ denote the state at $t$ and $s^{t}=\left(s_{t}, s_{t-1}, \ldots, s_{0}\right)$ denote the history. This is a complete markets model where a full set of state contingent bonds with payoffs in Country 1 money are traded internationally. A continuum of monopolistically competitive firms each produce a differentiated product using only labor. Ownership of the firms is not internationally traded. Hence, households of country $j=1,2,3$ own their country's firms and claims to their profits. Household resources accrue from firm profits, $\Pi_{j}\left(s^{t}\right)$, sales of labor, $n_{j}\left(s^{t}\right)$, previously unspent money balances, $M_{j}\left(s^{t}\right)$, and payoffs from the state-contingent bonds.

Let $C_{j}\left(s^{t}\right)$ be the household's consumption index (elaboration of the composition of the index follows below), let $P_{j}\left(s^{t}\right)$ be the general price level, $Q\left(s_{t+1} \mid s^{t}\right)$ be the Country 1 currency price of a statecontingent security, $W_{j}\left(s^{t}\right)$ be the nominal wage, $B_{j}\left(s_{t}\right)$ the number of state $s_{t}$ securities held, and $e_{i, j}\left(s^{t}\right)$ be the nominal exchange rate expressed as the Country $i$ currency price of a unit of Country $j$ money. Households face the sequential budget constraints

$$
\begin{aligned}
C_{j}\left(s^{t}\right)+\frac{M_{j}\left(s^{t}\right)}{P_{j}\left(s^{t}\right)}+\sum_{s_{t+1}} \frac{Q\left(s_{t+1} \mid s^{t}\right) B_{j}\left(s_{t+1}\right)}{e_{1, j}\left(s^{t}\right) P_{j}\left(s^{t}\right)} & =\frac{W_{j}\left(s^{t}\right) n_{j}\left(s^{t}\right)}{P_{j}\left(s^{t}\right)}+\frac{\Pi_{j}\left(s^{t}\right)}{P_{j}\left(s^{t}\right)} \\
& +\frac{M_{j}\left(s^{t-1}\right)}{P_{j}\left(s^{t}\right)}+\frac{B_{j}\left(s_{t}\right)}{e_{1, j}\left(s^{t}\right) P_{j}\left(s^{t}\right)},
\end{aligned}
$$

where current period resources are on the right side and uses of those resources on the left side of (10).

Preferences are defined over consumption $C_{j}\left(s^{t}\right)$, leisure $\left(1-n_{j}\left(s^{t}\right)\right)$, and real money balances $M_{j}\left(s^{t}\right) / P_{j}\left(s^{t}\right)$. The functional form for flow utility is

$$
\begin{aligned}
u\left(C_{j}\left(s^{t}\right),\left(1-n_{j}\left(s^{t}\right)\right), \frac{M_{j}\left(s^{t}\right)}{P_{j}\left(s^{t}\right)}\right) & =\left(\frac{C_{j}\left(s^{t}\right)^{1-\gamma_{1}}-1}{1-\gamma_{1}}\right)+\theta_{2}\left(\frac{\left(1-n_{j}\left(s^{t}\right)\right)^{1-\gamma_{2}}-1}{1-\gamma_{2}}\right) \\
& +\theta_{3}\left(\frac{\left(M_{j}\left(s^{t}\right) / P_{j}\left(s^{t}\right)\right)^{1-\gamma_{3}}-1}{1-\gamma_{3}}\right) .
\end{aligned}
$$

A household in country $j=1,2,3$ will maximize lifetime expected utility

$$
\sum_{t=0}^{\infty} \beta^{t} \sum_{s^{t}} \pi\left(s^{t}\right) u\left(C_{j}\left(s^{t}\right),\left(1-n_{j}\left(s^{t}\right)\right), \frac{M_{j}\left(s^{t}\right)}{P_{j}\left(s^{t}\right)}\right)
$$

subject to eq.(10) and the functional form eq.(11). Optimal behavior is characterized by the Euler equations

$$
\begin{aligned}
\theta_{2}\left(1-n_{j}\left(s^{t}\right)\right)^{-\gamma_{2}} & =\frac{W_{j}\left(s^{t}\right)}{P_{j}\left(s^{t}\right)} C_{j}\left(s^{t}\right)^{-\gamma_{1}} \\
\theta_{3}\left(\frac{M_{j}\left(s^{t}\right)}{P_{j}\left(s^{t}\right)}\right)^{-\gamma_{3}} & =\frac{i_{j}\left(s^{t}\right)}{1+i_{j}\left(s^{t}\right)} C_{j}\left(s^{t}\right)^{-\gamma_{1}}, \\
Q\left(s_{t+1} \mid s^{t}\right) & =\beta \pi\left(s_{t+1} \mid s^{t}\right)\left(\frac{C_{j}\left(s^{t+1}\right)}{C_{j}\left(s^{t}\right)}\right)^{-\gamma_{1}}\left(\frac{P_{j}\left(s^{t}\right)}{P_{j}\left(s^{t+1}\right)}\right)\left(\frac{e_{i, j}\left(s^{t}\right)}{e_{i, j}\left(s^{t+1}\right)}\right) .
\end{aligned}
$$


Because the state securities are denominated in Country 1 currency, using eq.(15), we obtain the consumption Euler equation,

$$
\frac{1}{1+i_{j}\left(s^{t}\right)}=\beta E_{t}\left(\frac{C_{j}\left(s^{t+1}\right)}{C_{j}\left(s^{t}\right)}\right)^{-\gamma_{1}}\left(\frac{P_{j}\left(s^{t}\right)}{P_{j}\left(s^{t+1}\right)}\right)\left(\frac{e_{1, j}\left(s^{t}\right)}{e_{1, j}\left(s^{t+1}\right)}\right) .
$$

Also, from eq.(15) and assuming that the law-of-one price across countries for state-contingent securities holds, we obtain the real exchange rate between $i$ and $j$,

$$
q_{i, j}\left(s^{t}\right)=\left(\frac{e_{i, j}\left(s^{t}\right) P_{j}\left(s^{t}\right)}{P_{i}\left(s^{t}\right)}\right)=h_{i, j, 0}\left(\frac{C_{j}\left(s^{t}\right)}{C_{i}\left(s^{t}\right)}\right)^{-\gamma_{1}},
$$

where

$$
h_{i, j, 0}=\left(\frac{e_{i, j}\left(s_{0}\right) P_{j}\left(s_{0}\right)}{P_{i}\left(s_{0}\right)}\right)\left(\frac{C_{i}\left(s_{0}\right)}{C_{j}\left(s_{0}\right)}\right)^{-\gamma_{1}} .
$$

Due to the complete-markets environment, the real exchange rate in this model (as did Benigno (2004) and Chari et al. (2002)) has the Backus-Smith (1993) form.

\subsection{The Demand System}

The household's consumption problem is broken into two parts. The first part is the intertemporal decision of expenditures and savings discussed in subsection 2.1. The second part is a cost-minimizing problem for allocating consumption expenditures across the different choices of goods, which we now describe.

Unless it is required to avoid confusion, we lighten the notation here by dropping the functional dependence on the state. The underlying goods are differentiated on a unit interval continuum with Country 1 producing goods on $\omega \in\left[0, a_{1}\right)$, Country 2 on $\omega \in\left[a_{1}, a_{2}\right)$ and Country 3 on $\omega \in\left[a_{2}, 1\right]$ $\left(0<a_{1}<a_{2}<1\right)$. Our notational convention is that the first subscript indicates where the good is consumed and the second subscript indicates where the good is produced $\left(C_{i, j, t}\right.$ is produced in $j$ and exported to $i$ at time $t$ ). The consumption index for the household of Country $j$ is formed by the CES (constant elasticity of substitution) index

$$
C_{j, t}=\left(\left(d_{j, 1}\right)^{\frac{1}{\mu}}\left(C_{j, 1, t}\right)^{\frac{\mu-1}{\mu}}+\left(d_{j, 2}\right)^{\frac{1}{\mu}}\left(C_{j, 2, t}\right)^{\frac{\mu-1}{\mu}}+\left(d_{j, 3}\right)^{\frac{1}{\mu}}\left(C_{j, 3, t}\right)^{\frac{\mu-1}{\mu}}\right)^{\frac{\mu}{\mu-1}},
$$

of consumption subindices and $0 \leq \mu \leq \infty$ is the elasticity of substitution and $d_{j, 1}+d_{j, 2}+d_{j, 3}=1$. The general price level associated with this consumption index is

$$
P_{j, t}=\left(d_{j, 1}\left(P_{j, 1, t}\right)^{1-\mu}+d_{j, 2}\left(P_{j, 2, t}\right)^{1-\mu}+d_{j, 3}\left(P_{j, 3, t}\right)^{1-\mu}\right)^{\frac{1}{1-\mu}} .
$$

Each of the underlying $C_{i, j, t}$ are themselves CES indices of the individual goods purchased, $c_{i, j, t}(\omega)$, from country $j$ and consumed by residents of country $i$,

$$
C_{i, j, t}=\left\{\begin{array}{cc}
\left(\left(\frac{1}{a_{1}}\right)^{\frac{1}{\sigma}} \int_{0}^{a_{1}} c_{i, j, t}(\omega)^{\frac{\sigma-1}{\sigma}} d \omega\right)^{\frac{\sigma}{\sigma-1}} & j=1 \\
\left(\left(\frac{1}{a_{2}-a_{1}}\right)^{\frac{1}{\sigma}} \int_{a_{1}}^{a_{2}} c_{i, j, t}(\omega)^{\frac{\sigma-1}{\sigma}} d \omega\right)^{\frac{\sigma}{\sigma-1}} & j=2 . \\
\left(\left(\frac{1}{1-a_{2}}\right)^{\frac{1}{\sigma}} \int_{a_{2}}^{1} c_{i, j, t}(\omega)^{\frac{\sigma-1}{\sigma}} d \omega\right)^{\frac{\sigma}{\sigma-1}} & j=3
\end{array}\right.
$$


Also, each of the underlying $P_{i, j, t}$ are themselves CES indices of the individual good prices, $p_{i, j, t}(\omega)$, produced in country $j$ and consumed by residents of country $i$,

$$
P_{i, j, t}=\left\{\begin{array}{cl}
\left(\left(\frac{1}{a_{1}}\right) \int_{0}^{a_{1}} p_{i, j, t}(\omega)^{1-\sigma} d \omega\right)^{\frac{1}{1-\sigma}} & j=1 \\
\left(\left(\frac{1}{a_{2}-a_{1}}\right) \int_{a_{1}}^{a_{2}} p_{i, j, t}(\omega)^{1-\sigma} d \omega\right)^{\frac{1}{1-\sigma}} & j=2 . \\
\left(\left(\frac{1}{1-a_{2}}\right) \int_{a_{1}}^{a_{2}} p_{i, j, t}(\omega)^{1-\sigma} d \omega\right)^{\frac{1}{1-\sigma}} & j=3
\end{array} .\right.
$$

The solution to the cost-minimization problem gives the demand functions for the underlying goods

$$
c_{i, j, t}(\omega)=\phi_{i, j, t}\left(\frac{p_{i, j, t}(\omega)}{P_{i, j}, t}\right)^{-\sigma} C_{i, t}
$$

where

$$
\phi_{i, j, t}=\left\{\begin{array}{cc}
\left(\frac{d_{i, 1}}{a_{1}}\right)\left(\frac{P_{i, 1, t}}{P_{i, t}}\right)^{-\mu} & j=1 \\
\left(\frac{d_{i, 2}}{a_{2}-a_{1}}\right)\left(\frac{P_{i, 2, t}}{P_{i, t}}\right)^{-\mu} & j=2 \\
\left(\frac{d_{i, 3}}{1-a_{2}}\right)\left(\frac{P_{i, 3, t}}{P_{i, t}}\right)^{-\mu} & j=3
\end{array} .\right.
$$

\subsection{The Firm's Problem}

Firms in country $j$ have access to a linear (in labor input) technology

$$
y_{j, t}(\omega)=A_{j, t} n_{j, t}(\omega),
$$

where $A_{j, t}$ is an economy-wide technology shock and $n_{j, t}(\omega)$ is the labor input into producing commodity $\omega .^{7}$ The firm's output is demand determined so that

$$
y_{j, t}(\omega)=c_{1, j, t}(\omega)+c_{2, j, t}(\omega)+c_{3, j, t}(\omega) .
$$

Real current period profits for a firm in country $j$ is

$$
\Pi_{j, t}(\omega)=\sum_{i=1}^{3} \frac{e_{j, i, t}}{P_{j, t}} p_{i, j, t}(\omega) c_{i, j, t}(\omega)-\frac{W_{j, t}}{P_{j, t}} n_{j, t}(\omega) .
$$

Substituting $n_{j, t}(\omega)$ from eq. (19), $y_{j, t}(\omega)$ from eq. (20) and the individual goods demands from eq. (18) into eq. (21) gives current period profits as

$$
\Pi_{j, t}(\omega)=\sum_{i=1}^{3}\left(\frac{e_{j, i, t}}{P_{j, t}} p_{i, j, t}(\omega)-\frac{W_{j, t}}{A_{j, t} P_{j, t}}\right) \phi_{i, j, t}\left(\frac{p_{i, j, t}(\omega)}{P_{i, j, t}}\right)^{-\sigma} C_{i, t} .
$$

Firms engage in local-currency pricing and prices are sticky in the sense of Calvo (1983). We introduce heterogeneity in price stickiness by country of origin. That is, firms of Country $j$ can reset prices of all its sales (whether they be domestic sales or exports) with probability $\left(1-\alpha_{j}\right)$. A firm in country $j$ who is chosen to reset price this period does so to maximize

$$
E_{t} \sum_{k=0}^{\infty}\left(\alpha_{j} \beta\right)^{k} C_{j, t+k}^{-\gamma_{1}} \Pi_{j, t+k}(\omega),
$$

\footnotetext{
${ }^{7}$ National output is $Y_{1, t}=\int_{0}^{a_{1}} y_{1, t}(\omega) d \omega, Y_{2, t}=\int_{a_{1}}^{a_{2}} y_{2, t}(\omega) d \omega$, and $Y_{3, t}=\int_{a_{2}}^{1} y_{3, t}(\omega) d \omega$.
} 
subject to (22). Rearrangement of the first-order condition gives the optimal price for the country $j$ firm who sells its product in country $i$ as

$$
p_{i, j, t}^{*}(\omega)=\frac{\sigma}{(\sigma-1)} \frac{E_{t} \sum_{k=0}^{\infty}\left(\alpha_{j} \beta\right)^{k} C_{i, t+k} C_{j, t+k}^{-\gamma_{1}} \phi_{i, j, t+k} P_{i, j, t+k}^{\sigma} \frac{W_{j, t+k}}{A_{j, t+k} P_{j, t+k}}}{E_{t} \sum_{k=0}^{\infty}\left(\alpha_{j} \beta\right)^{k} C_{i, t+k} C_{j, t+k}^{-\gamma_{1}} \phi_{i, j, t+k} P_{i, j, t+k}^{\sigma} \frac{e_{j, i, t+k}}{P_{j, t+k}}} .
$$

With the fraction $\left(1-\alpha_{j}\right)$ of the firms resetting price to the value of $p_{i, j, t}^{*}(\omega)$ and the fraction $\alpha_{j}$ that maintain price at the previous level, the price index of goods produced in $j$ and sold in $i$ evolves according to

$$
P_{i, j, t}=\left(1-\alpha_{j}\right) p_{i, j, t}^{*}+\alpha_{j} P_{i, j, t-1}
$$

\subsection{Monetary Policy}

The monetary authorities conduct policy through interest rate reaction functions. We consider two variants of policy conduct-independent and managed float. Under independence, countries pursue only domestic objectives so that authorities in country $j=1,2,3$ set their interest rates according to

$$
i_{j, t}=\delta+\rho i_{j, t-1}+\lambda E_{t} \pi_{j, t+1}+\phi \tilde{y}_{j, t}+\epsilon_{j, t}
$$

We include the lagged interest rate to model interest rate smoothing by the authorities. In a second variant, which we'll refer to as "managed float," Countries 1 and 3 run policy according to eq.(25) but Country 2's policy function also includes the real exchange rate between 2 and 3,

$$
i_{2, t}=\delta+\rho i_{2, t-1}+\lambda E_{t} \pi_{2, t+1}+\phi \tilde{y}_{2, t}+\sigma q_{2,3, t}+\epsilon_{2, t},
$$

which is the form studied in Section 1.1 Here, purchasing power parity is viewed as the equilibrium for the nominal exchange rate and the authorities intervene to stabilize the exchange rate against Country 3 around the PPP value.

\subsection{Equilibrium}

Equilibrium requires that national outputs $Y_{j, t}$, be consumed,

$$
Y_{j, t}= \begin{cases}\int_{0}^{a_{1}} y_{1, t}(\omega) d \omega=\sum_{i=1}^{3} C_{i, 1, t} & j=1 \\ \int_{a_{1}}^{a_{2}} y_{2, t}(\omega) d \omega=\sum_{i=1}^{3} C_{i, 2, t} & j=2 \\ \int_{a_{2}}^{1} y_{3, t}(\omega) d \omega=\sum_{i=1}^{3} C_{i, 3, t} & j=3\end{cases}
$$

and labor supply be allocated,

$$
n_{j, t}=\left\{\begin{array}{cc}
\int_{0}^{a_{1}} n_{1, t}(\omega) d \omega & j=1 \\
\int_{a_{1}}^{a_{2}} n_{2, t}(\omega) d \omega & j=2 . \\
\int_{a_{2}}^{1} n_{3, t}(\omega) d \omega & j=3
\end{array} .\right.
$$

An equilibrium for this economy is a collection of allocations for households of $C_{j, t}, n_{j, t}, M_{j, t}, B_{j}\left(s_{t}\right)$, allocations and prices for producers, $y_{j, t}$ and $p_{i, j, t}$, final goods prices, $P_{j, t}$, wages, $W_{j, t}$, and bond prices, 
$Q\left(s^{t+1} \mid s_{t}\right)$, such that the household allocations solve the household's problem, goods prices solve the producer's problem, market clearing conditions hold, and monetary policies are conducted as described above.

We specify the exogenous monetary shocks to be $\epsilon_{j, t} \stackrel{i i d}{\sim}\left(0, \sigma_{\epsilon}^{2}\right)$ processes and the technology shocks to be univariate first-order autoregressive processes with no spill-overs,

$$
\ln \left(A_{j, t}\right)=\psi \ln \left(A_{j, t-1}\right)+\nu_{j, t}
$$

where $\nu_{j, t} \stackrel{i i d}{\sim}\left(0, \sigma_{\nu}^{2}\right)$.

\subsection{Solution Method and Parameterization}

We take a first-order approximation around the zero-inflation steady state and then solve the model numerically. The derivation of the approximated model is given in the appendix. Our model parameterization, which is summarized in Table 1, draws on values used in the literature and assumes that a period is one quarter. We begin with a benchmark specification of symmetry in price setting and policy rules. Here, we set $\alpha_{j}=0.75$ for $j=1,2,3$, which corresponds to firms updating prices, on average, once per year. To examine the importance of heterogeneity in price stickiness across countries, we set $\alpha_{1}=0.407, \alpha_{2}=0.89$, and $\alpha_{3}=0.65$, which follows from Benigno (2004). The subjective discount factor is set at $\beta=0.99$ which implies an annualized steady state interest rate of four percent. Preference parameters for consumption $\left(\gamma_{1}\right)$, leisure $\left(\gamma_{2}\right)$, and real money balances $\left(\gamma_{3}\right)$ are all set at $2 .{ }^{8}$ There is no home bias in consumption $\left(d_{j, k}=\frac{1}{3}\right.$ for $\left.j, k=1,2,3\right)$. Also, following Benigno (2004), we set the elasticity of substitution between domestic and foreign goods $(\mu)$ to 1.5 .

The persistence of the exogenous productivity process $(\psi)$ is set to 0.9. For the monetary policy rules we assume that the monetary policy interest rate is persistent, with a coefficient $(\rho)$ equal to 0.95 . We assume that the central bank adjusts the policy rate more than one-for-one with changes in inflation $(\lambda=1.5)$, but less than one-for-one with movements in the output gap $(\phi=0.5)$, as is standard in the literature. Anticipating our empirical results of the estimated interest rate feedback Taylor rules, we set $\sigma=0.5$.

\section{Third-Country Effects on the Exchange Rate between Coun- tries 1 and 2}

This section studies third-country effects on the exchange rate implied by the model. The analysis proceeds in two parts. First, we conduct an impulse response analysis for the nominal and real exchange rates between countries 1 and $2\left(e_{1,2}\right.$ and $\left.q_{1,2}\right)$. Our primary interest is in observing the magnitude of the impact responses of $e_{1,2}$ and $q_{1,2}$ to Country 3 shocks relative to Country 1 and Country 2 shocks. We find that the third-country effects can be relatively important when Countries 1 and 2 differ either in their monetary policy rules or in the degree of price stickiness.

\footnotetext{
${ }^{8} \gamma_{1}$ is the coefficient of relative risk aversion. Chari, Kehoe, and McGrattan (2002) set this coefficient to five in order to generate the desired volatility in exchange rates, which is on the high end of macroeconomic estimates.
} 
The second part of our analysis examines the potential improvement in explanatory power provided by third-country fundamentals in the sorts of exchange rate regressions used in the empirical literature. The empirical evidence is that macroeconomic fundamentals for Countries 1 and 2 have very little explanatory and/or predictive power for exchange rates between Countries 1 and 2. Our hypothesis is that an important part of the exchange rate disconnect puzzle is due to ignorance of third country effects. We investigate this idea by running regressions of exchange rates on macroeconomic fundamentals from countries 1, 2, and 3 using data that we generate from the model. We find increased explanatory power by including third-country macroeconomic fundamentals in our standard two country regressions.

\subsection{Impulse Response Analysis}

Environment I: Independent monetary policy; symmetric price setting. We present impulse responses in an environment of symmetric monetary policies and price stickiness to establish a benchmark set of results against which responses under asymmetries can be compared. ${ }^{9}$ These benchmark results for the exchange rate between 1 and 2 are identical to predictions that would be obtained from a two-country model under symmetry. As mentioned above, there are no third-country effects on the exchange rate, $e_{12}$ or $q_{12}$, when the countries are completely symmetric.

Figure 1 shows impulse responses of $e_{1,2}$ and $q_{1,2}$ from a positive technology shock. The favorable Country 1 technology shock generates Country 1 deflation as improved efficiency leads 1's firms to cut prices on home sales as well as on exports. Country 2 (and 3) experiences inflation as its firms raise prices in response to increasing demand. The divergent inflation responses lead the real interest rate to fall in 1 and to rise in 2. Relative consumption in 1 increases resulting in both real and nominal depreciations from Country 1's perspective (increases in $q_{1,2}$ and $e_{1,2}$ ).

Figure 2 shows impulse responses to monetary policy (tightening) shocks. Monetary tightening in 1 causes its currency to appreciate relative to 2. $e_{1,2, t}$ and $q_{1,2, t}$ fall upon impact and there is instantaneous overshooting of the nominal exchange rate. The initial policy shock is persistent on account of interest rate smoothing which keeps 1's real interest rate above 2's for several periods. This pushes $C_{1}$ below $C_{2}$ which results in a Country 1 real and nominal appreciation relative to Country 2.

Environment II. Managed float with symmetric price setting. We introduce asymmetries in monetary policy rules by assuming that Country 2 pursues a managed float against Country 3's currency. Price stickiness across countries remains identical. We begin with exchange rate responses to technology shocks, which are shown in Figure 3.

A favorable technology shock in Country 1 produces the same responses from $e_{1,2}$ and $q_{1,2}$ as under environment I (independent policy, symmetric price setting). This is because the Country 1 shock affects 2 and 3 identically and therefore has no effect on $q_{2,3}$ so the fact that 2 manages its exchange rate against 3 is of no consequence for the exchange rate between 1 and 2 .

\footnotetext{
${ }^{9}$ As mentioned earlier, shocks from Country 3 have no effect on the exchange rate between 1 and 2 . Because the exchange rate depends on Country 2 variables relative to Country 1 variables, under symmetry, these variables respond in exactly the same way to Country 3 shocks which render the exchange rate unaffected.
} 
A favorable technology shock in Country 2 produces initial responses of $e_{1,2}$ and $q_{1,2}$ that are qualitatively the same as under environment I, but of smaller magnitude. Country 2's technology improvement lowers its marginal cost. Country 2 firms respond by lowering prices which leads to a period of deflation in 2. Countries 1 and 3 experience inflation as their firms raise prices of domestic sales and of exports to each other in response to rising demand. The relatively low Country 2 real interest rate and relatively high consumption in 2 relative to 3 generates a real Country 2 depreciation (increase in $q_{2,3}$ ), to which the monetary authorities respond. This depreciation causes 2 's interest rate to be higher than it would be if it were not managing the exchange rate. The managed float policy response attenuates the increase in $C_{2}$ and therefore 2's depreciation against 1.

Under Environment II, we observe that third-country technology shocks can have measurable effects on the exchange rate. A favorable technology shock in Country 3 produces an initial real and nominal appreciation of currency 1 relative to 2 . The initial impact on the exchange rate between 1 and 2 is of the same order of magnitude as the impact effect of a Country 2 technology shock. The Country 3 technology shock generates Country 3 deflation and increases consumption and Country 2 inflation (firms in 1 and 2 raise prices of domestic sales and exports to each other). This raises $C_{3}$ above $C_{2}$, and a real Country 2 appreciation relative to 3 ( $q_{2,3}$ falls). Part of the managed float policy response in 2 is to lower the interest rate whereas the real interest rate in 1 increases as monetary policy in 1 reacts primarily to increased inflation, $C_{2}$ rises above $C_{1}$ resulting in a Country 1 real and nominal appreciation relative to 2 (decrease in $q_{1,2}$ and $e_{1,2}$ ).

Figure 4 shows the exchange rate responses to monetary policy shocks. The responses of $e_{1,2}$ and $q_{1,2}$ following a Country 1 monetary policy (tightening) shock are not much different here than under environment I. The tightening affects Countries 2 and 3 symmetrically, which has no effect on $q_{2,3}$ and hence no difference in 2's policy response.

Following a monetary policy shock in Country 2, the initial responses of $e_{1,2}$ and $q_{1,2}$ are dampened relative to the response under environment I. Country 2's tightening initially generates a real appreciation in 2 relative to 1 and 3, but the decrease in $q_{2,3}$ causes 2's central bank to loosen. This subsequent loosening attenuates the effects of the initial shock on 2's exchange rate with 1.

A surprise monetary tightening by Country 3 generates the same qualitative response in $e_{1,2}$ and $q_{1,2}$ as that from a Country 2 monetary tightening but of a larger magnitude. The tightening in 3 raises $q_{2,3}$ on impact. This causes 2 to raise its interest rate which leads to an appreciation of 2 relative to 1 (an increase in $e_{1,2}$ and $q_{1,2}$ ).

One of the more compelling results that we have seen thus far is that third country shocks can have quantitatively important effects on the exchange rate. These results have been obtained by assuming that shock volatility is the same across countries. To see how varying relative shock volatility of Country 3 affects the volatility of the depreciation $\left(\Delta e_{1,2}\right)$, see Figure 5. To form a basis of comparison, we also show the effect of varying the volatility of Country 2 shocks. ${ }^{10}$ On the left, we show the effect of varying the size of technology shocks. The line marked with symbols shows the relative increase in exchange

\footnotetext{
${ }^{10}$ This is comparing the contribution to exchange rate (depreciation) volatility by the third country in a three-country model to the contribution from a second country in a two-country model.
} 
rate depreciation volatility (measured as the standard deviation) for a relative increase in the volatility of Country 2 technology shocks obtained from a symmetric two-country model. The solid line shows the analogous information when varying the volatility of Country 3's technology shock under a Country 2 managed float. At 0.0 on the horizontal axis, the volatility of 1 and 2's technology shocks are equal. At 1.0, 2's technology shock is twice as volatile as 1's. Doubling the importance (volatility) of Country 3 is more than half as important as doubling the importance of Country 2 in a two-country model.

The right side of Figure 5 shows analogous computations for monetary policy shocks. A doubling of policy shock volatility contributes less to exchange rate volatility than a doubling of technology shock volatility. However, we see a similar contribution to exchange rate volatility (between 1 and 2) generated by increasing Country 3 policy volatility relative to increasing Country 2 volatility in a two-country environment; it is about half the size.

Environment III. Independent monetary policies with asymmetric price stickiness. This environment assumes asymmetric reset price probabilities with independent monetary policies (no exchange rate management). Country 2 firms experience the most price stickiness, followed by country 3 , and lastly country $1\left(\alpha_{2}=0.89>\alpha_{3}=0.65>\alpha_{1}=0.407\right)$. Figure 6 shows the exchange rate responses to technology shocks. They are considerably different from those obtained under the symmetric price stickiness case of environment I. The indirect channel created by price-stickiness asymmetries results in Country 3 shocks generating $e_{1,2}$ and $q_{1,2}$ responses of the same order of magnitude as shocks originating in Countries 1 and 2.

Following the Country 1 technology shock, there is only a tiny impact effect on the real and nominal exchange rates but there is a delayed appreciation of 1's currency relative to 2 . This contrasts with the response under Environment I where 1's technology shock initially led to a depreciation of 1 relative to 2. Under Environment I, $r_{2}$ increases and $r_{1}$ declines upon impact. Higher $C_{1}$ and lower $C_{2}$ result in a Country 1 depreciation (increase $q_{1,2}$ ) upon impact. As seen on the left panel of Figure 7 , under Environment III, $r_{2}$ declines initially and the resulting effect on $C_{2}$ mitigates the initial effect on the exchange rate. The reason $r_{2}$ declines here is because of the initial impact on inflation. Country 1 firms lower prices while Country 2 and 3 firms initially raise prices. Relatively few Country 2 firms can change price initially. Even if the price declines in 1's exports to 2 were the same as they were under Environment I, the lack of price movement by 2's firms now leads to a bigger initial deflation in 2 .

Following a technology shock in Country 2 , the responses of $e_{1,2}$ and $q_{1,2}$ are both qualitatively and quantitatively similar to the responses under Environment I. Here, $r_{1}$ increases upon impact (as under Environment I) because Country 1 initially experiences some inflation. Country 1 and 3 firms increase prices, but due to sluggish price cuts from Country 2 firms, the end result is inflation. The decline in $r_{2}$ and increase in $r_{1}$ cause relative consumption levels and the exchange rate between 1 and 2 to respond similarly to the responses under Environment I.

The technology shock of primary interest is a shock to Country 3. In the symmetric environment, the favorable Country 3 technology shock results in deflation in 3 and inflation in 1 and 2. Here, Country 1 firms raise prices and Country 3 firms lower prices, but there is, at least initially, relatively little price response by Country 2 firms. Since Country 2 firms do not raise prices on exports to 1 or 
3 by much, the demand for 2's goods increase as does 2's output gap. As a result of the endogenous monetary policy response, $r_{2}$ lies above $r_{1}$, consumption of 1 lies above consumption of 2 and $e_{1,2}$ and $q_{1,2}$ increase. The impulse responses of the real interest rates to the Country 3 shock are shown in the right panel of Figure 7 .

Turning now to monetary policy shocks, the response of $e_{1,2}$ and $q_{1,2}$ to policy shocks originating in Countries 1 and 2 are qualitatively the same as those obtained under the fully symmetric model of Environment I. However, a Country 3 monetary tightening now generates a decline in $e_{1,2}$ and $q_{1,2}$. In the symmetric environment both $r_{1}$ and $r_{2}$ decrease by the same amount in response to 3's tightening. Here, with price-stickiness heterogeneities, $r_{2}$ declines by more than $r_{1}$, primarily because of differences in output gap responses. Because Country 2's firm prices are the stickiest, it experiences the largest (negative) output gap whereas Country 1 experiences the smallest gap. The endogenous monetary policy response in 1 and 2 is to lower the interest rate in 2 by more than in 1 . Consumption in 2 is higher than consumption in 1 which implies a decline in $e_{1,2}$ and $q_{1,2}$.

The impulse response analysis has shown how bilateral exchange rates may fluctuate in response to third-country shocks. These results suggest that third-country macro variables might be important omitted variables in exchange rate prediction regressions. We now turn to address this issue directly.

\subsection{Exchange Rates and Third-Country Fundamentals}

In this subsection, we use the three-country model as the data-generating mechanism to study its implications for exchange rate regressions employed in empirical research. In addition to Environments II and III, we also combine the managed float between Countries 2 and 3 with cross-country heterogeneity in price stickiness (Environment IV). For each environment, we generate $N=6000$ samples of length $T=40$. The length of the time series is set to correspond to the (approximately) 40 quarterly observations used in our empirical work below. We compare the mean $\bar{R}^{2}$ from regressions of the exchange rate between 1 and 2 that condition only on variables from 1 and 2 and regressions that also condition on Country 3 variables.

We examine both DPPP regressions and Taylor-rule fundamentals regressions. In the DPPP regressions, we compare the $\bar{R}^{2}$ between

$$
\hat{e}_{1,2, t+k}-\hat{e}_{1,2, t}=b_{0}+b_{1} \hat{q}_{1,2, t}+\epsilon_{1,2, t+k},
$$

and

$$
\hat{e}_{1,2, t+k}-\hat{e}_{1,2, t}=b_{0}+b_{1} \hat{q}_{1,2, t}+b_{2} \hat{q}_{2,3, t}+\epsilon_{1,2, t+k},
$$

where the 'hats' are exchange rates in logarithmic form. Eq.(29) regresses the $k$-period (proportionate) change in the exchange rate between 1 and 2 on the DPPP between those two countries, which is a restricted error-correction specification that has been found to be a relatively successful specification. Eq.(30) adds Country 3 information by including the DPPP between 2 and 3 as a conditioning variable.

The results for the DPPP regressions are shown in Table 2. For each of the environments that generate the data, the $\bar{R}^{2}$ increases when third-country information, $\hat{q}_{2,3}$, is introduced into the regression. 
The $\bar{R}^{2}$ improvements are modest under Environment II, but are consequential under Environments III and IV, especially for predictive regressions at the four-period horizon $(k=4)$. Under Environment IV, when Country 3 variables are included, the mean $\bar{R}^{2}$ increases from 0.01 to 0.07 at the one-period horizon and from 0.14 to 0.35 at the four-period horizon .

In the Taylor-rule fundamentals regressions, we compare the $\bar{R}^{2}$ between

$$
\hat{e}_{1,2, t+k}-\hat{e}_{1,2, t}=b_{0}+b_{1} \pi_{1, t}+b_{2} \pi_{2, t}+b_{3} \tilde{y}_{1, t}+b_{4} \tilde{y}_{2, t}+\epsilon_{1,2, t+k},
$$

and

$$
\hat{e}_{1,2, t+k}-\hat{e}_{1,2, t}=b_{0}+b_{1} \pi_{1, t}+b_{2} \pi_{2, t}+b_{3} \tilde{y}_{1, t}+b_{4} \tilde{y}_{2, t}+b_{5} \pi_{3, t}+b_{6} \tilde{y}_{3, t}+\epsilon_{1,2, t+k} .
$$

Eq.(31) is the standard Taylor-rule fundamentals regression that conditions on inflation and the output gaps of countries 1 and 2. Eq.(32) augments with Country 3 inflation and the output gap.

The results for this experiment are shown in Table 3. Here, we also find an increase in the $\bar{R}^{2}$ values when Country 3 variables are added to the regression. Under Environment IV, which admits both policy and price-stickiness heterogeneity, the $\bar{R}^{2}$ increases by 32 percent (from 0.16 to 0.21 ) at the one-period horizon and by 45 percent (from 0.37 to 0.54 ) at the four-period horizon when Country 3 variables are included.

Thus, the model predicts that third-country variables should be included in exchange rate regressions. In the next section, we investigate whether the data supports this prediction.

\section{Supporting Empirical Evidence}

This section presents empirical support for the model. Subsection 4.1 reports estimates of monetary policy reaction functions for a variety of countries and finds evidence consistent with non-USD exchange rate management. In section 4.2, we use data to estimate the predictive exchange rate regressions (29)(32). Using the data, we find (as we did with the Monte Carlo exercise) that the introduction of third-country conditioning information results in considerable increases in regression $\bar{R}^{2}$.

\subsection{Evidence on Cross-Rate Management}

Our policy rates are from Datastream. ${ }^{11}$ We construct the output gap as the deviation of log of industrial production from the Hodrick-Prescott filtered trend. Inflation is measured by the rate of increase in the CPI.

We draw on Greenaway-McGrevey et al. (2012) to guide our choice of candidate currencies of cross-rate management. Engel et al. (2012) and Greenaway-McGrevey et al. (2012) find, in a panel of exchange rates against the U.S. dollar, that these exchange rates have a three-factor representation.

\footnotetext{
${ }^{11}$ The interest rates used for the countries in our analysis are as follows. Brazil, Selic target rate. Canada, Bank of Canada rate. Denmark, interbank one-month offered rate. Great Britain, UK clearing banks base rate. Indonesia, BI rate and interbank rate. Japan, uncollateralized overnight rate. Philippines, reverse repo and interbank call loan rate. Switzerland, 3 month LIBOR. Thailand, interbank overnight rate. Singapore, interbank one-month rate. The euro, ECB interest rate. The U.S., Federal Funds rate.
} 
Greenaway-McGrevey et al. are able to identify these common factors as the USD/euro, the USD/Swiss franc, and the USD/yen exchange rates. Their identification of the Swiss franc and the yen as factors accords with their role as 'safe haven' currencies. Their identification of the USD/euro as the dominant factor makes sense because the euro is one of the most highly traded currencies. Since the institutional structure under which exchange rates are determined is clearly different after the adoption of the euro, we confine our analysis to the time period after the euro's formal launch to blunt complications arising from estimation spanning different regimes. The observations are quarterly and span from 1999Q1 to 2011Q4. Candidate currencies for cross-rate management are the euro, the Swiss franc, and the yen.

As in Clarida et al. $(1998,2000)$, we allow for interest rate smoothing by the authorities in the empirical work. If the target rate $i_{t}^{T}$ is given by eq. (2), interest rate smoothing of the policy rate is represented as $i_{t}=\rho i_{t-1}+(1-\rho) i_{t}^{T}$. Hence we estimate monetary policy feedback rules of the form

$$
i_{t}=\delta+\rho i_{t-1}+(1-\rho)\left(\lambda E_{t} \pi_{t+1}+\phi \tilde{y}_{t}+\sigma \hat{q}_{x, t}\right)+\epsilon_{t}
$$

where $\hat{q}_{x, t}$ is the log real exchange rate between the country in question and either the euro, the Swiss franc, or the yen. Estimation is performed by substituting $E_{t} \pi_{t+1}=\pi_{t+1}+v_{t+1}$ in eq. (33) where $v_{t+1}$ is the rational expectations forecast error, and estimating the resulting equation by generalized method of moments. We use the lagged policy rate and current and three lagged values of inflation, the output gap, and real exchange rates as instruments.

Table 4 reports the estimation results. The table reports estimates and t-ratios for $\sigma$ which is the coefficient of primary interest (the full set of estimation results is provided in the Appendix). For each country, the estimates are obtained from separate regressions. The cross-rate management term always shows up with the predicted sign and is almost always statistically significant. ${ }^{12}$ In some cases (e.g., Brazil), the evidence is consistent with exchange rate management against more than one currency. In many cases, estimated coefficients on expected inflation and/or the output gap are either insignificant and/or have signs inconsistent with conventional notions of inflation targeting or of the Taylor rule. Bergin (2006), who estimated his model on a smaller set of countries, reported similar findings. ${ }^{13}$

To summarize, our estimates provide evidence of monetary policy induced heterogeneity across countries that may generate third-country effects on bi-lateral exchange rates. In the next subsection, we ask if third-country variables can improve $\bar{R}^{2}$ of exchange rate predictive regressions estimated with data.

\subsection{Third-Country Effects in Exchange Rate Prediction Equations}

In this subsection, we use data to estimate eqs.(29)-(32) to produce the data counterpart to Table 2. Table 5 reports the results for the DPPP regressions. Estimation is performed on the same set of countries used in the empirical analysis of monetary policy reaction functions.

\footnotetext{
${ }^{12}$ Quarterly industrial production data were not available for Indonesia, Norway, the Philippines, Thailand and Singapore.

${ }^{13}$ It is not the purpose of this work to paint a complete picture of monetary policy around the world, and we are not arguing that any country in particular does or does not violate the Taylor principle, for example, in its conduct of monetary policy-that is acts with a policy feedback rule with $\lambda<1$.
} 
For each country, we first regress the $k$-period ahead nominal depreciation against the USD on that country's DPPP against the U.S. At the one-period horizon, the real exchange rate relative to the USD often has a negative adjusted $R^{2}$. We then add to this regression the DPPP against the euro, the yen, or the Swiss franc. Even though estimation of policy feedback rules may not have found that the policy rate responds to a particular cross rate (we did not find that Denmark's interest rate reacted to the krone/yen rate, for example), our model provides an indirect channel for cross-rates to enter. As can be seen, augmenting the regression with a cross-rate real exchange rate raises the $\bar{R}^{2}$ in the majority of the cases. The magnitude of the improvement is consistent with what was implied by the model.

The results from the 4-period horizon are more dramatic. The increase in the $\bar{R}^{2}$, both in terms of raw levels and as a proportion, obtained by introducing cross-rate DPPPs in many cases exceed what is predicted by the model.

Table 6 reports results from the Taylor-rule fundamentals regression. Here, the $\bar{R}^{2}$ usually increases when either Swiss or Japanese variables are added to the regression and almost always increases when Euro-area variables are added. The exceptions at the one-period horizon are Brazil, Denmark (somewhat surprisingly), and Thailand. Overall, our empirical results are consistent with the theory's predictions in Table 3.

\section{Conclusion}

The low explanatory power of empirical exchange rate models has long been an awkward presence for many elegant macro-based theories. This empirical work typically takes its guidance from exchange rate theory, which itself is usually written down in a two-country setting. Hence, the empirical research has mostly been conducted on a bilateral basis. That is, macroeconomic variables from a specific pair of countries are investigated to explain their bilateral exchange rate. However, the data are generated in a multi-country environment, and it is possible that innovations arising from some other country, beyond the pair under consideration, will have effects on their exchange rate. If this is the case, then there is an omitted variables problem in exchange rate regressions that condition only on bilateral country variables, and incorporating third-country variables into empirical specifications should result in improved explanatory power.

In this paper, we characterize the exchange rate disconnect puzzle by the low adjusted $R^{2}$ in shorthorizon exchange rate prediction regressions that are popular in the literature. We find merit, both theoretically and empirically, in the idea that third-country omitted variables are at least partly responsible for the puzzle. In the theoretical work, using a three-country DSGE exchange rate model, third country shocks are shown to have relatively large effects on bilateral exchange rates. Additionally, including third-country variables raise adjusted $R^{2}$ in these regressions. The model also provides (at least) one theory for recent econometric findings that common factors explain a large proportion of bilateral exchange rate variation. In the empirical work, using data for twelve countries, we find empirical support for the model's predictions.

Our analysis makes measurable progress towards resolving the disconnect puzzle, but is not a com- 
plete solution (we do not obtain $\bar{R}^{2}$ values near 1 ). While we confine our study to the role of macroeconomic fundamentals in a very standard context, we acknowledge that there is room for microstructure considerations (e.g., Lyons, 2001) and non-fundamental influences (e.g., Mark and Wu, 1998, Jeanne and Rose, 2002, and Evans, 2012) to further improve our understanding of exchange rate movements. 


\section{References}

[1] Backus, David K. and Gregor W. Smith, 1993. "Consumption and Real Exchange Rates in Dynamic Economies with Non-Traded Goods," Journal of International Economics, 35: $297-316$.

[2] Benigno, Gianluca, 2004. "Real Exchange Rate Persistence and Monetary Policy Rules," Journal of Monetary Economics, 51: 473-502.

[3] Bergin, Paul R., 2006. "How Well Can the New Open Economy Macroeconomics Explain the Exchange Rate and Current Account?" Journal of International Money and Finance, 25: 675-701.

[4] Calvo, G.A., 1983. "Staggered Prices in a Utility-Maximizing Framework," Journal of Monetary Economics, 12: 393-398.

[5] Chari, V.V, Patrick J. Kehoe and Ellen R. McGrattan, 2002. "Can Sticky Price Models Generate Volatile and Persistent Real Exchange Rates?" Review of Economic Studies, 69: $533-563$.

[6] Chinn, Menzie and Richard Meese, 1995. "Banking on Currency Forecasts: Is Change in Money Predictable?" Journal of International Economics 38:161-78.

[7] Chinn, Menzie, Yin-Wong Cheung and Antonio Garcia Pascual, 2005. "Empirical Exchange Rate Models of the Nineties: Are Any Fit to Survive?" Journal of International Money and Finance 24: 1150-1175.

[8] Clarida, Richard, Jordi Gali, and Mark Gertler. (1998) "Monetary Policy Rules in Practice: Some International Evidence." European Economic Review, 42, 1033-67.

[9] Clarida, Richard, Jordi Gali, and Mark Gertler. (2000) "Monetary Policy Rules and Macroeconomic Stability: Evidence and Some Theory." Quarterly Journal of Economics, $147-80$.

[10] Engel, Charles and Kenneth D. West, 2006. "Taylor Rules and the Deutschemark-Dollar Real Exchange Rate," Journal of Money, Credit, and Banking, 38: 1175-1194.

[11] Engel, Charles, Nelson C. Mark and Kenneth D. West, 2007. "Exchange Rate Models Are Not As Bad As You Think," NBER Macroeconomics Annual 2007, 22: 381-441.

[12] Engel, Charles, Nelson C. Mark and Kenneth D. West, 2012. "Factor Model Forecasts of Exchange Rates," mimeo, University of Wisconsin, Madison.

[13] Evans, Martin D.D., 2012. "Exchange-Rate Dark Matter," mimeo, Georgetown University.

[14] Greenaway-Mcgrevy, Ryan, Nelson C. Mark, Donggyu Sul and Jyh-lin Wu, 2012. "Exchange Rates as Exchange Rate Common Factors," mimeo, University of Notre Dame.

[15] Groen, Jan J. J. 2005. "Exchange rate predictability and monetary fundamentals in a small multi-country panel," Journal of Money, Credit and Banking 37:495-516. 
[16] Hodrick, Robert and Maria Vassalou, 2002. "Do We Need Multi-Country Models to Explain Exchange Rate and Interest Rate and Bond Return Dynamics?" Journal of Economic Dynamics and Control, 26: 1275-1299.

[17] Jeanne, Olivier and Andrew Rose, 2002. "Noise Trading and Exchange Rate Regimes," Quarterly Journal of Economics, 177: 537-569.

[18] Kollman, Robert, 2001. "The Exchange Rate in a Dynamic-Optimizing Business Cycle Model with Nominal Rigidities: A Quantitative Investigation," Journal of International Economics, 55: 243-262.

[19] Mark, Nelson C. 1995. "Exchange Rates and Fundamentals: Evidence on Long-Horizon Predictability," American Economic Review, 85: 201-218.

[20] Mark, Nelson C. and Yangru Wu, 1998. "Rethinking Deviations from Uncovered Interest Parity: The Role of Covariance Risk and Noise," Economic Journal, 108: 1686-1706.

[21] Mark, Nelson C and Dongguy Sul. 2001. "Nominal exchange rates and monetary fundamentals: Evidence from a small post-Bretton Woods sample," Journal of International Economics 53:29-52.

[22] Mark, Nelson C. 2009. "Changing Monetary Policy Rules, Learning, and Real Exchange Rate Dynamics," Journal of Money, Credit, and Banking, 41:1047-1070.

[23] Molodtsova, Tanya and David H. Papell, 2009. "Out-of-sample exchange rate predictability with Taylor rule fundamentals," Journal of International Economics, 77: 167-80.

[24] Molodtsova, Tanya, Alex Nikolsko- Rzhevskyy and David H. Papell, 2008. "Taylor Rules with Real-Time Data: A Tale of Two Countries and One Exchange Rate," Journal of Monetary Economics, 55: S63-S79.

[25] Molodtsova, Tanya, Alex Nikolsko- Rzhevskyy and David H. Papell, "Taylor-rules and the Euro," Journal of Money, Credit, and Banking, 535-552.

[26] Obstfeld, Maurice and Kenneth Rogoff, 2000. "The Six Major Puzzles in International Macroeconomics: Is There a Common Cause?" NBER Macroeconomics Annual, 2000, 15: 339-412.

[27] Lyons, Richard K. 2001. The Microstructure Approach to Exchange Rates, MIT Press.

[28] Rapach, David E., and Mark E. Wohar. 2002. "Testing the monetary model of exchange rate determination: New evidence from a century of data," Journal of International Economics 58:359-85.

[29] Sokolov, Vladimir, 2012. "Bi-currency versus Single-currency Targeting: Lessons from the Russian Experience," forthcoming, Review of International Economics.

[30] Steinsson, Jon, 2008. "The Dynamic Behavior of the Real Exchange Rate in Sticky Price Models," American Economic Review, 98: 519-533. 
Figure 1. Exchange rate response to technology shock under Environment I

(independent policy, symmetric stickiness)

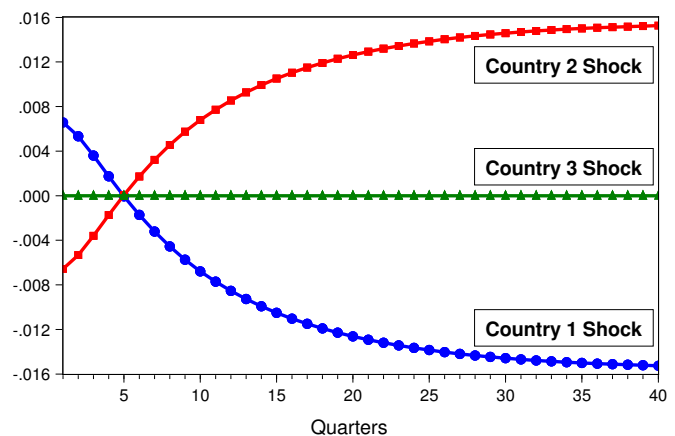

Nominal exchange rate $\left(e_{1,2}\right)$ response

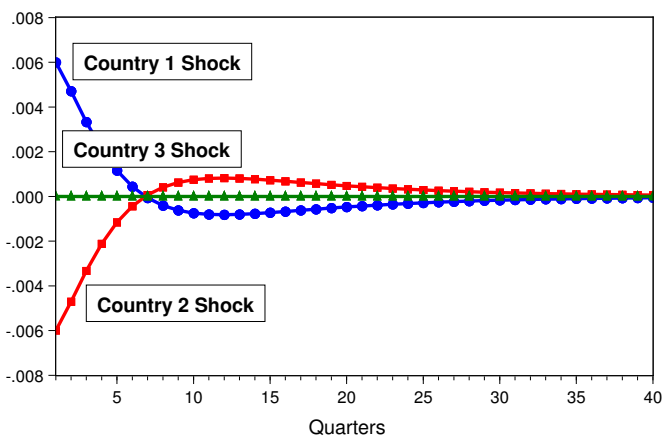

Real exchange rate $\left(q_{1,2}\right)$ response

Figure 2. Exchange rate response to monetary policy shock under Environment I

(independent policy, symmetric stickiness)

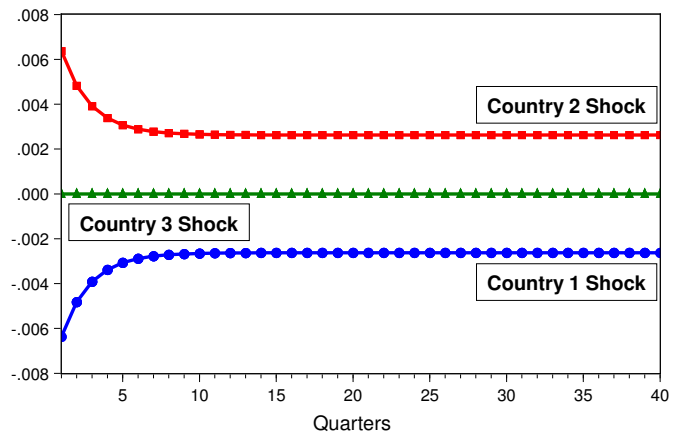

Nominal exchange rate $\left(e_{1,2}\right)$ response

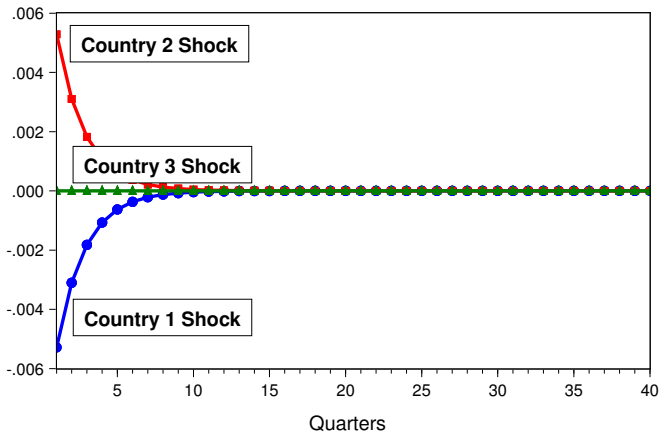

Real exchange rate $\left(q_{1,2}\right)$ response

Figure 3. Exchange rate response to technology shock under Environment II (managed float between 2 and 3, symmetric stickiness)

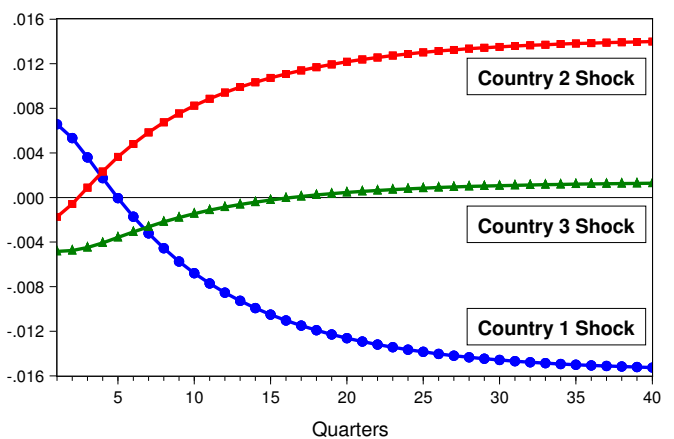

Nominal exchange rate $\left(e_{1,2}\right)$ response

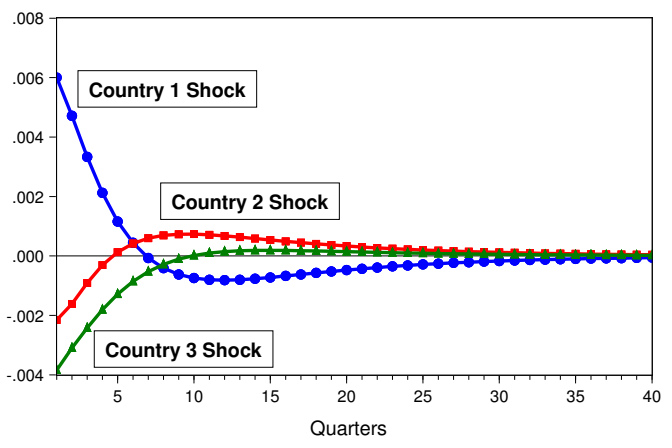

Real exchange rate $\left(q_{1,2}\right)$ response 
Figure 4: Exchange rate response to policy shock under Environment II (managed float between 2 and 3, symmetric stickiness)

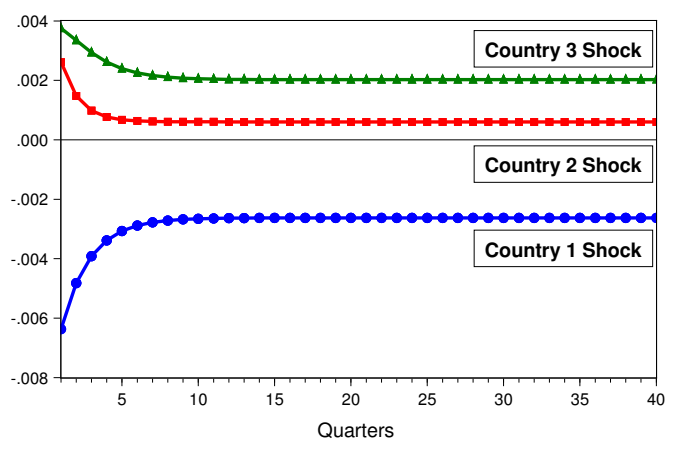

Nominal exchange rate $\left(e_{1,2}\right)$ response

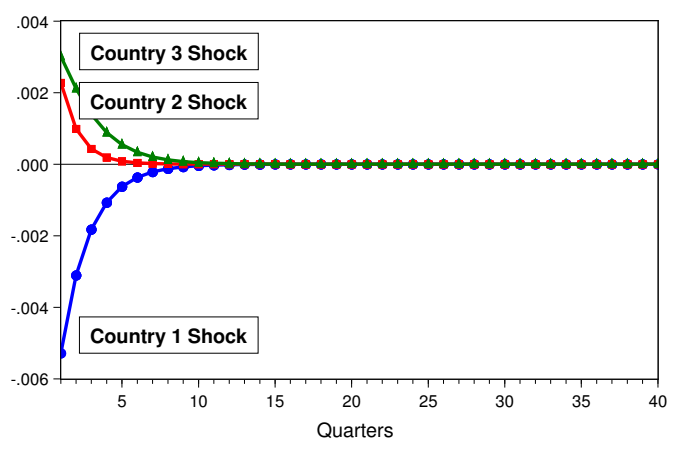

Real exchange rate $\left(q_{1,2}\right)$ response

Figure 5: Volatility of $\Delta e_{1,2}$ and relative volatility of Country 2 and 3 shocks
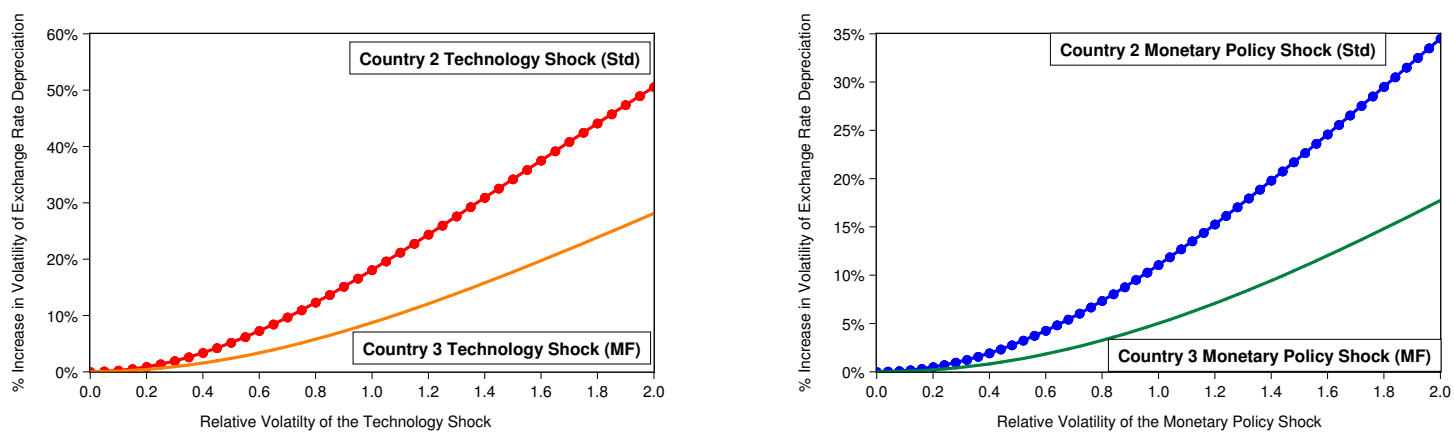

Figure 6: Exchange rate response to technology shocks under Environment III (independent policy, heterogeneous stickiness by origin)

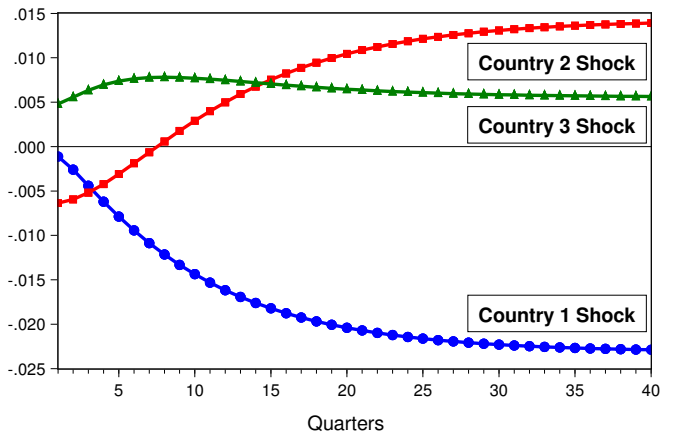

Nominal exchange rate $\left(e_{1,2}\right)$ response

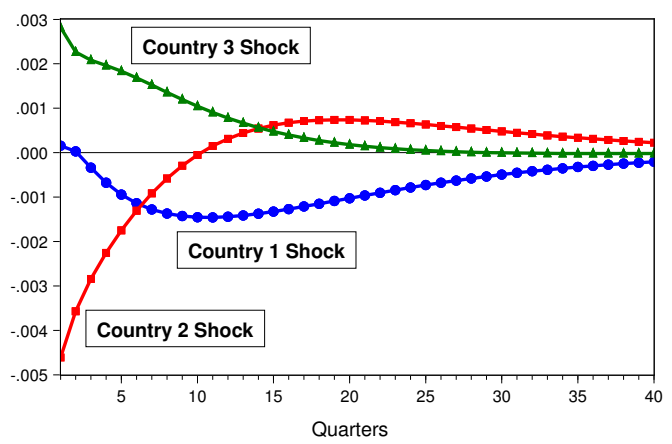

Real exchange rate $\left(q_{1,2}\right)$ response 
Figure 7: Real interest rate response to technology shock under Environment III (independent policy, heterogeneous stickiness by origin)

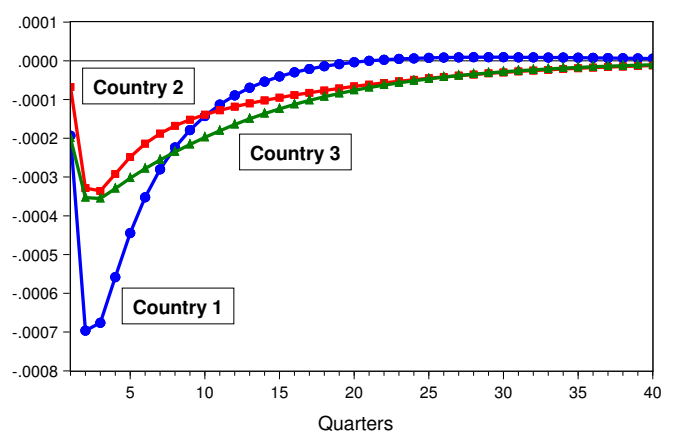

Response to Country 1 shock

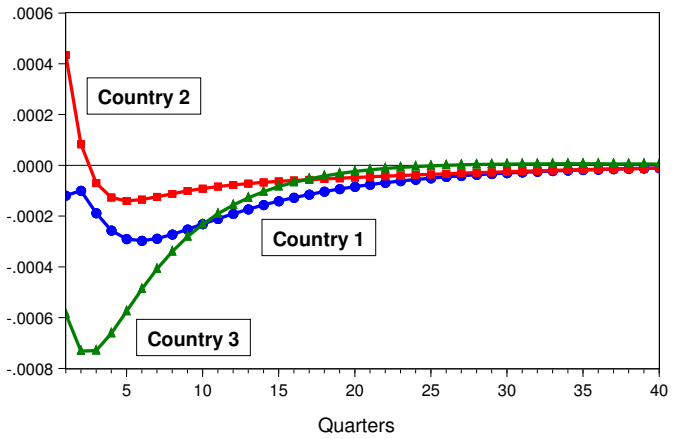

Response to Country 3 shock

Figure 8: Exchange rate response to monetary policy shocks under Environment III (independent policy, heterogeneous stickiness by origin)

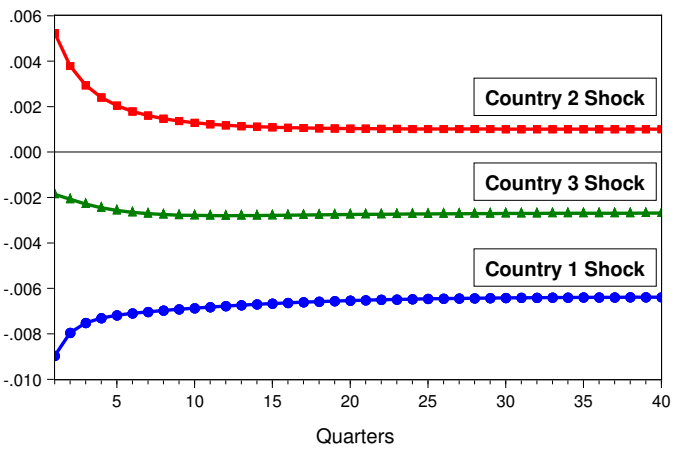

Nominal exchange rate $\left(e_{1,2}\right)$ response

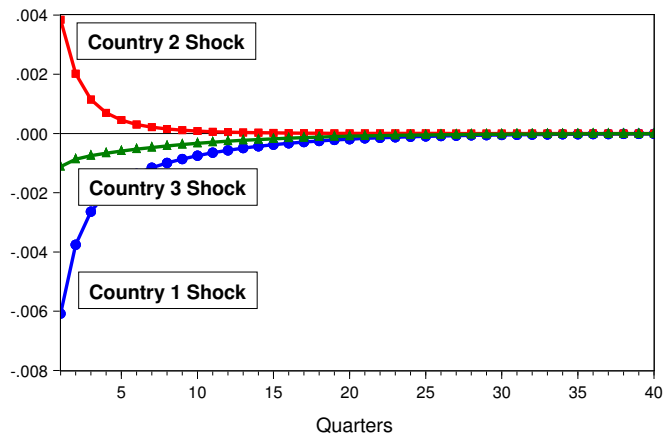

Real exchange rate $\left(q_{1,2}\right)$ response 
Table 1: Parameterization

\begin{tabular}{|c|c|c|c|}
\hline \multirow[b]{2}{*}{$\gamma_{1}$} & \multirow{2}{*}{$\frac{\text { Preferences }}{2}$} & $\underline{\text { Symmetric Price Setting }}$ & Monetary Policy \\
\hline & & $\alpha_{j} \quad 0.75 \quad(j=1,2,3)$ & $\rho \quad 0.95$ \\
\hline$\gamma_{2}$ & 2 & & $\lambda \quad 1.5$ \\
\hline$\gamma_{3}$ & 2 & Asymmetric Price Setting & $\phi \quad 0.5$ \\
\hline$d_{i, j}$ & $(i, j=1,2,3)$ & $\begin{array}{ll}\alpha_{1} & 0.407\end{array}$ & 0.5 \\
\hline \multirow[t]{3}{*}{$\beta$} & 0.99 & $\alpha_{2} \quad 0.890$ & \\
\hline & & $\alpha_{3} \quad 0.650$ & Technology \\
\hline & & & $\psi \quad 0.9$ \\
\hline
\end{tabular}

Table 2: Monte Carlo Mean $\bar{R}^{2}$ from PPP Predictive Regressions

\begin{tabular}{cccc}
\hline \hline & & 2 Country Model & 3 Country Model \\
Horizon & Environment & $\bar{R}^{2}$ & $\bar{R}^{2}$ \\
\hline 1 & II & 0.018 & 0.059 \\
1 & III & 0.014 & 0.057 \\
1 & IV & 0.012 & 0.065 \\
\hline 4 & II & 0.171 & 0.349 \\
4 & III & 0.157 & 0.337 \\
4 & IV & 0.140 & 0.345 \\
\hline \hline
\end{tabular}


Table 3: Monte Carlo Mean $\bar{R}^{2}$ from Taylor-Rule Fundamentals Regressions

\begin{tabular}{cccc}
\hline \hline & & 2 Country Model & 3 Country Model \\
Horizon & Environment & $\bar{R}^{2}$ & $\bar{R}^{2}$ \\
\hline 1 & II & 0.061 & 0.089 \\
1 & III & 0.122 & 0.170 \\
1 & IV & 0.155 & 0.206 \\
\hline 4 & II & 0.249 & 0.337 \\
4 & III & 0.335 & 0.520 \\
4 & IV & 0.369 & 0.538 \\
\hline \hline
\end{tabular}

Table 4: Cross-Rate Management.

Estimates of equation management coefficient in eq.(33)

Newey-West t-ratios in parentheses

\begin{tabular}{lccccc}
\hline \hline Country & Cross rate & $\sigma$ & Country & Cross rate & $\sigma$ \\
\hline Brazil & euro & $0.301^{* *}$ & Japan & euro & $0.016^{* *}$ \\
& & $(3.664)$ & & & $(3.274)$ \\
& SF & $0.359^{* *}$ & Norway & yen & $0.013^{*}$ \\
& & $(4.573)$ & & & $(1.885)$ \\
& yen & $0.267^{* *}$ & Philippines & euro & $0.103^{* *}$ \\
& & $(4.780)$ & & & $(3.260)$ \\
Canada & \multirow{2}{*}{ euro } & $0.084^{*}$ & & yen & $0.069^{* *}$ \\
& & $(1.849)$ & & & $(2.399)$ \\
Denmark & \multirow{2}{*}{ euro } & $0.769^{* *}$ & Switzerland & euro & $0.065^{* *}$ \\
& & $(4.616)$ & & & $(3.141)$ \\
UK & \multirow{2}{*}{ yen } & $0.047^{*}$ & Thailand & euro & 0.124 \\
& & $(1.844)$ & & & $(1.531)$ \\
Indonesia & yen & $0.072^{* *}$ & Singapore & yen & 0.160 \\
& & $(2.320)$ & & & $(1.234)$ \\
\hline \hline
\end{tabular}

Notes: * $\left.{ }^{* *}\right)$ indicates significance at the $10(5)$ percent level. 
Table 5: $\bar{R}^{2}$ from DPPP Exchange Rate Regressions

\begin{tabular}{lcccc}
\hline \hline & \multicolumn{4}{c}{ DPPP relative to } \\
Country & USD & USD \& euro & USD \& yen & USD \& SF \\
\cline { 2 - 4 } & $\bar{R}^{2}$ & $\bar{R}^{2}$ & $\bar{R}^{2}$ & $\bar{R}^{2}$ \\
\hline Brazil & -0.016 & $\mathbf{0 . 0 9 7}$ & $\mathbf{0 . 0 8 8}$ & -0.036 \\
Canada & -0.015 & $\mathbf{- 0 . 0 0 6}$ & -0.030 & $\mathbf{0 . 0 1 3}$ \\
Denmark & -0.003 & $\mathbf{0 . 0 0 0}$ & $\mathbf{0 . 1 2 4}$ & -0.024 \\
Great Britain & 0.042 & 0.024 & $\mathbf{0 . 0 6 1}$ & 0.024 \\
Indonesia & -0.010 & $\mathbf{- 0 . 0 0 7}$ & -0.010 & $\mathbf{0 . 0 2 7}$ \\
Japan & 0.045 & 0.035 & & 0.033 \\
Norway & -0.004 & $\mathbf{0 . 0 3 3}$ & $\mathbf{0 . 0 0 8}$ & $\mathbf{0 . 0 5 4}$ \\
Philippines & -0.021 & $\mathbf{0 . 0 3 8}$ & $\mathbf{0 . 0 7 0}$ & $\mathbf{0 . 0 2 9}$ \\
Singapore & -0.021 & -0.029 & $\mathbf{0 . 0 4 5}$ & -0.025 \\
Switzerland & -0.018 & -0.033 & $\mathbf{0 . 0 4 1}$ & \\
Thailand & -0.016 & $\mathbf{0 . 0 0 0}$ & $\mathbf{0 . 0 6 5}$ & $\mathbf{- 0 . 0 0 8}$ \\
& & Four-period horizon & \\
Brazil & 0.038 & $\mathbf{0 . 4 8 8}$ & $\mathbf{0 . 4 2 9}$ & 0.032 \\
Canada & 0.009 & $\mathbf{0 . 0 4 2}$ & $\mathbf{0 . 0 1 3}$ & $\mathbf{0 . 1 0 0}$ \\
Denmark & 0.070 & $\mathbf{0 . 1 2 6}$ & $\mathbf{0 . 4 8 5}$ & 0.062 \\
Great Britain & 0.250 & $\mathbf{0 . 2 5 4}$ & $\mathbf{0 . 3 4 6}$ & 0.243 \\
Indonesia & 0.216 & $\mathbf{0 . 2 7 3}$ & $\mathbf{0 . 3 3 6}$ & $\mathbf{0 . 3 2 4}$ \\
Japan & 0.199 & $\mathbf{0 . 2 1 9}$ & & $\mathbf{0 . 2 5 8}$ \\
Norway & 0.070 & 0.061 & $\mathbf{0 . 2 3 9}$ & 0.064 \\
Philippines & -0.008 & $\mathbf{0 . 1 4 6}$ & $\mathbf{0 . 2 2 6}$ & $\mathbf{0 . 1 6 3}$ \\
Singapore & 0.003 & $\mathbf{0 . 0 9 5}$ & $\mathbf{0 . 1 4 7}$ & $\mathbf{0 . 1 2 4}$ \\
Switzerland & 0.017 & -0.001 & $\mathbf{0 . 2 5 6}$ & \\
Thailand & -0.013 & $\mathbf{0 . 0 4 1}$ & $\mathbf{0 . 2 9 7}$ & $\mathbf{0 . 0 6 9}$ \\
\hline \hline
\end{tabular}

Note: Bold face entries indicate that addition of third-country variables increase $\bar{R}^{2}$. 
Table 6: $\bar{R}^{2}$ from Taylor-Rule Exchange Rate Regressions

\begin{tabular}{|c|c|c|c|c|}
\hline \multirow[b]{3}{*}{ Country } & \multicolumn{4}{|c|}{ Taylor-Rule Fundamentals of Home Country and } \\
\hline & U.S. & U.S. \& Euro & U.S. \& Japan & U.S. \& Switz. \\
\hline & $\bar{R}^{2}$ & $\bar{R}^{2}$ & $\bar{R}^{2}$ & $\bar{R}^{2}$ \\
\hline & \multicolumn{4}{|c|}{ One-period horizon } \\
\hline Brazil & 0.068 & 0.060 & 0.030 & 0.126 \\
\hline Canada & 0.079 & 0.084 & 0.144 & 0.115 \\
\hline Denmark & -0.041 & -0.086 & 0.177 & -0.045 \\
\hline Great Britain & 0.099 & 0.155 & 0.078 & 0.111 \\
\hline Indonesia & 0.023 & -0.012 & 0.078 & 0.041 \\
\hline Japan & 0.011 & 0.038 & & -0.030 \\
\hline Norway & 0.066 & 0.079 & 0.058 & 0.027 \\
\hline Philippines & -0.047 & 0.072 & -0.077 & -0.051 \\
\hline Singapore & -0.043 & 0.037 & -0.050 & 0.046 \\
\hline Switzerland & -0.073 & 0.169 & -0.114 & \\
\hline \multirow[t]{2}{*}{ Thailand } & 0.054 & 0.045 & 0.034 & 0.021 \\
\hline & \multicolumn{4}{|c|}{ Four-period horizon } \\
\hline Brazil & -0.017 & 0.053 & 0.001 & 0.253 \\
\hline Canada & 0.491 & 0.494 & 0.468 & 0.738 \\
\hline Denmark & 0.208 & 0.278 & 0.265 & 0.249 \\
\hline GreatBritain & 0.270 & 0.333 & 0.336 & 0.275 \\
\hline Indonesia & 0.396 & 0.382 & 0.386 & 0.380 \\
\hline Japan & -0.013 & 0.045 & & -0.063 \\
\hline Norway & 0.323 & 0.426 & 0.309 & 0.338 \\
\hline Philippines & -0.003 & 0.112 & 0.061 & 0.135 \\
\hline Singapore & 0.095 & 0.157 & 0.073 & 0.164 \\
\hline Switzerland & 0.085 & 0.295 & 0.152 & \\
\hline Thailand & 0.182 & 0.167 & 0.160 & 0.192 \\
\hline
\end{tabular}

Note: Bold face entries indicate that addition of third-country variables increase $\bar{R}^{2}$. 


\section{Appendix (not intended for publication)}

The first section of the appendix gives the derivations of the first-order approximation of the model around the deterministic and zero-inflation steady state. The second section reports reports estimates and robust t-ratios of all coefficients in monetary policy rules.

\section{Equations of the Model}

We begin with a listing of the equations of the model and their first-order approximations around the steady state. This is followed up by the derivations. To simplify the notation, we drop the explicit dependence on the state. For $i, j=1,2,3$, we have from the consumer's problem,

$$
\begin{aligned}
& \theta_{2}\left(1-n_{j, t}\right)^{-\gamma_{2}}=\frac{W_{j, t}}{P_{j, t}}\left(C_{j, t}\right)^{-\gamma_{1}} \\
& \theta_{3}\left(\frac{M_{j, t}}{P_{j, t}}\right)^{-\gamma_{3}}=\frac{i_{j, t}}{1+i_{j, t}}\left(C_{j, t}\right)^{-\gamma_{1}} \\
& \frac{1}{1+i_{j . t}}=\beta E_{t}\left(\frac{C_{j, t+1}}{C_{j, t}}\right)^{-\gamma_{1}}\left(\frac{P_{j, t}}{P_{j, t+1}}\right) \\
& \frac{1}{1+i_{1 . t}}=\beta E_{t}\left(\frac{C_{j, t+1}}{C_{j, t}}\right)^{-\gamma_{1}}\left(\frac{P_{j, t}}{P_{j, t+1}}\right)\left(\frac{e_{i, j, t}}{e_{i, j, t+1}}\right) \\
& q_{i, j . t}=\left(\frac{e_{i, j, t} P_{j, t}}{P_{i, t}}\right)=h_{i, j, 0}\left(\frac{C_{j, t}}{C_{i, t}}\right)^{-\gamma_{1}} \\
& e_{i, j, t}=\frac{q_{i, j, t} P_{i, t}}{P_{j, t}} \\
& C_{j, t}=\left[\sum_{i=1}^{3}\left(d_{j, i}\right)^{\frac{1}{\mu}}\left(C_{j, i, t}\right)^{\left(\frac{\mu-1}{\mu}\right)}\right]^{\frac{\mu}{\mu-1}} \\
& C_{i, j, t}=d_{i, j}\left(\frac{P_{i, j, t}}{P_{i, t}}\right)^{-\mu} C_{i, t} \\
& c_{i, j, t}(\omega)=\left\{\begin{array}{cl}
\frac{d_{i, 1}}{a_{1}}\left(\frac{p_{i, 1, t}(\omega)}{P_{i, 1, t}}\right)^{-\sigma}\left(\frac{P_{i, 1, t}}{P_{i}, t}\right)^{-\mu} C_{i, t} & j=1 \\
\frac{d_{i, 2}}{a_{2}-a_{1}}\left(\frac{p_{i, 2, t}(\omega)}{P_{i, 2, t}}\right)^{-\sigma}\left(\frac{P_{i, 2, t}}{P_{i, t}}\right)^{-\mu} C_{i, t} & j=2 \\
\frac{d_{i, 3}}{1-a_{2}}\left(\frac{p_{i, 3, t}(\omega)}{P_{i, 3, t}}\right)^{-\sigma}\left(\frac{P_{i, 3, t}}{P_{i, t}}\right)^{-\mu} C_{i, t} & j=3
\end{array}\right. \\
& P_{j, t}=\left[\sum_{i=1}^{3} d_{j, i} P_{j, i}^{1-\mu}\right]^{\frac{1}{1-\mu}} \\
& P_{i, j, t}=\left\{\begin{array}{cc}
\left(\frac{1}{a_{1}} \int_{0}^{a_{1}} p_{i, 1}(\omega)^{(1-\sigma)} d \omega\right)^{\frac{1}{1-\sigma}} & j=1 \\
\left(\frac{1}{a_{2}-a_{1}} \int_{a_{1}}^{a_{2}} p_{i, 2}(\omega)^{(1-\sigma)} d \omega\right)^{\frac{1}{1-\sigma}} & j=2 \\
\left(\frac{1}{1-a_{2}} \int_{a_{2}}^{1} p_{i, 3}(\omega)^{(1-\sigma)} d \omega\right)^{\frac{1}{1-\sigma}} & j=3
\end{array}\right.
\end{aligned}
$$

From the firm's pricing problem, we have 


$$
\begin{aligned}
& F_{i, j, t}\left(E_{t} \sum_{k=0}^{\infty}\left(\alpha_{i} \beta\right)^{k} C_{i, t+k} C_{j, t+k}^{-\gamma_{1}} \phi_{i, j, t+k}\left(\frac{P_{i, j, t+k}}{P_{i, j, t}}\right)^{\sigma-1}\left(\frac{P_{i, j, t+k}}{P_{i, t+k}}\right) q_{j, i, t+k}\right) \\
= & \frac{\sigma}{(\sigma-1)}\left(E_{t} \sum_{k=0}^{\infty}\left(\alpha_{i} \beta\right)^{k} C_{i, t+k} C_{j, t+k}^{-\gamma_{1}} \phi_{i, j, t+k}\left(\frac{P_{i, j, t+k}}{P_{i, j, t}}\right)^{\sigma} \frac{W_{j, t+k}}{A_{j, t+k} P_{j, t+k}}\right)
\end{aligned}
$$

where $F_{i, j, t}=\frac{p_{i, j, t}^{*}}{P_{i, j, t}}$.

$$
y_{j, t}(\omega)=A_{j, t} n_{j, t}(\omega)
$$

We also have the market clearing conditions

$$
\begin{aligned}
& Y_{1, t}=\int_{0}^{a_{1}} y_{1, t}(\omega) d \omega=C_{1,1, t}+C_{2,1, t}+C_{3,1, t} \\
& Y_{2, t}=\int_{a_{1}}^{a_{2}} y_{2, t}(\omega) d \omega=C_{1,2, t}+C_{2,2, t}+C_{3,2, t} \\
& Y_{3, t}=\int_{a_{2}}^{1} y_{3, t}(\omega) d \omega=C_{1,3, t}+C_{2,3, t}+C_{3,3, t} \\
& \sum_{j=1}^{3} Y_{j, t}=\sum_{j=1}^{3} C_{j, t} \\
& n_{j, t}= \begin{cases}\int_{0}^{a_{1}} n_{1, t}(\omega) d \omega & j=1 \\
\int_{a_{1}}^{a_{2}} n_{2, t}(\omega) d \omega & j=2 \\
\int_{a_{2}}^{1} n_{3, t}(\omega) d \omega & j=3\end{cases}
\end{aligned}
$$

\section{The first-order approximated model}

$$
\begin{aligned}
& \hat{W}_{j, t}-\hat{P}_{j, t}= \gamma_{1} \hat{C}_{j, t}+\gamma_{2} \frac{n}{(1-n)} \hat{n}_{j, t} \\
& \hat{M}_{j, t}-\hat{P}_{j, t}= \frac{\gamma_{1}}{(1+\delta) \gamma_{3}} \hat{C}_{j, t}-\frac{(1-\delta)}{(1+\delta) \gamma_{3}} \hat{\imath}_{j, t} \\
& \hat{C}_{j, t}= E_{t}\left(\hat{C}_{j, t+1}-\frac{1}{\gamma_{1}}\left(\hat{\imath}_{j, t}-\hat{\pi}_{j, t+1}\right)\right) \\
& \hat{C_{j, t}}= E_{t}\left(\hat{C}_{j, t+1}-\frac{1}{\gamma_{1}}\left(\hat{i}_{1, t}-\Delta \hat{e}_{i, j, t+1}-\hat{\pi}_{j, t+1}\right)\right) \\
& \hat{q}_{i, j, t}=-\gamma_{1}\left(\hat{C}_{j, t}-\hat{C}_{i, t}\right) \\
& \hat{e}_{i, j, t}=\hat{q}_{i, j, t}+\left(\hat{P}_{i, t}-\hat{P}_{j, t}\right) \\
& \hat{C}_{j, t}=\sum_{i=1}^{3} d_{j, i} \hat{C}_{j, i, t} \\
& \hat{C}_{i, j, t}=\mu\left(\hat{P}_{i, t}-\hat{P}_{i, j, t}\right)+\hat{C}_{i, t}
\end{aligned}
$$




$$
\begin{gathered}
\hat{y}_{j, t}=\sum_{i=1}^{3} d_{i, j}\left(\mu\left(\hat{P}_{i, t}-\hat{P}_{i, j, t}\right)+\hat{C}_{i, t}\right) \\
\hat{P}_{j, t}=\sum_{i=1}^{3} d_{j, i} \hat{P}_{j, i, t} \\
\hat{y}_{j, t}=\hat{A}_{j, t}+\hat{n}_{j, t} \\
\pi_{i, j, t}=\frac{\left(1-\alpha_{i}\right)\left(1-\alpha_{i} \beta\right)}{\alpha_{i}}\left(\hat{m}_{j, t}-\hat{q}_{i, j, t}+\left(\hat{P}_{i, t}-\hat{P}_{i, j, t}\right)\right)+\beta E_{t} \pi_{i, j, t+1}
\end{gathered}
$$

where $\hat{m}_{j, t}=\hat{W}_{j, t}-\hat{A}_{j, t}-\hat{P}_{j, t}$ is the first-order approximation of marginal cost for Country $j$ firms.

$$
\begin{gathered}
\hat{P}_{i, t}-\hat{P}_{i, j, t}=\left\{\begin{array}{cc}
d_{i, 2}\left(\hat{P}_{i, 2, t}-\hat{P}_{i, 3, t}\right)+\left(1-d_{i, 1}\right)\left(\hat{P}_{i, 3, t}-\hat{P}_{i, 1, t}\right) & j=1 \\
d_{i, 1}\left(\hat{P}_{i, 1, t}-\hat{P}_{i, 3, t}\right)+\left(1-d_{i, 2}\right)\left(\hat{P}_{i, 3, t}-\hat{P}_{i, 2, t}\right) & j=2 \\
d_{i, 1}\left(\hat{P}_{i, 1, t}-\hat{P}_{i, 3, t}\right)+d_{i, 2}\left(\hat{P}_{i, 2, t}-\hat{P}_{i, 3, t}\right) & j=3
\end{array}\right. \\
\left(\hat{P}_{i, j, t}-\hat{P}_{k, u, t}\right)=\left(\hat{P}_{i, j, t-1}-\hat{P}_{k, u, t-1}\right)+\left(\pi_{i, j, t}-\pi_{k, u, t}\right)
\end{gathered}
$$

\section{Household problem}

Sum the pricing formula for the country 1 currency state-contingent bond (15) over states of nature to get (15) in the text,

$$
\sum_{s_{t+1}} Q\left(s_{t+1} \mid s^{t}\right)=\frac{1}{1+i_{1}\left(s^{t}\right)}=\beta E_{t}\left(\frac{C_{j, t+1}}{C_{j, t}}\right)^{-\gamma_{1}}\left(\frac{P_{j, t}}{P_{j, t+1}}\right)\left(\frac{e_{i, j, t}}{e_{i, j, t+1}}\right) .
$$

For country 1 , since $e_{11, t}=1$, we have simply,

$$
\frac{1}{1+i_{1, t}}=\beta E_{t}\left(\frac{C_{1, t+1}}{C_{1, t}}\right)^{-\gamma_{1}}\left(\frac{P_{1, t}}{P_{1, t+1}}\right)
$$

In addition, Countries 2 and 3 each have a non-traded, non-state contingent nominal bond in zero-net supply and the prices of these bonds are,

$$
\begin{aligned}
& \frac{1}{1+i_{2, t}}=\beta E_{t}\left(\frac{C_{2, t+1}}{C_{2, t}}\right)^{-\gamma_{1}}\left(\frac{P_{2, t}}{P_{2, t+1}}\right), \\
& \frac{1}{1+i_{3, t}}=\beta E_{t}\left(\frac{C_{3, t+1}}{C_{3, t}}\right)^{-\gamma_{1}}\left(\frac{P_{3, t}}{P_{3, t+1}}\right) .
\end{aligned}
$$

The real exchange rate (17) is obtained by taking the price of the state-contingent security priced by agents in countries $i$ and $j$

$$
\left(\frac{C_{i}\left(s^{t+1}\right)}{C_{i}\left(s^{t}\right)}\right)^{-\gamma_{1}}\left(\frac{P_{i}\left(s^{t}\right)}{P_{i}\left(s^{t+1}\right)}\right)\left(\frac{e_{1, i}\left(s^{t}\right)}{e_{1, i}\left(s^{t+1}\right)}\right)=\left(\frac{C_{j}\left(s^{t+1}\right)}{C_{j}\left(s^{t}\right)}\right)^{-\gamma_{1}}\left(\frac{P_{j}\left(s^{t}\right)}{P_{j}\left(s^{t+1}\right)}\right)\left(\frac{e_{1, j}\left(s^{t}\right)}{e_{1, j}\left(s^{t+1}\right)}\right),
$$

rearranging as

$$
\left(\frac{e_{i, j}\left(s^{t+1}\right) P_{j}\left(s^{t+1}\right)}{P_{i}\left(s^{t+1}\right)}\right)\left(\frac{C_{j}\left(s^{t+1}\right)}{C_{i}\left(s^{t+1}\right)}\right)^{\gamma_{1}}=\left(\frac{e_{i, j}\left(s^{t}\right) P_{j}\left(s^{t}\right)}{P_{i}\left(s^{t}\right)}\right)\left(\frac{C_{j}\left(s^{t}\right)}{C_{i}\left(s^{t}\right)}\right)^{\gamma_{1}},
$$


and performing repeated backward substitution to obtain

$$
q_{i, j}\left(s^{t}\right)=\left(\frac{e_{i, j}\left(s^{t}\right) P_{j}\left(s^{t}\right)}{P_{i}\left(s^{t}\right)}\right)=h_{i, j, 0}\left(\frac{C_{j}\left(s^{t}\right)}{C_{i}\left(s^{t}\right)}\right)^{-\gamma_{1}},
$$

where $h_{i, j}\left(s^{0}\right)=\left(\frac{e_{i, j}\left(s^{0}\right) P_{j}\left(s^{0}\right)}{P_{i}\left(s^{0}\right)}\right)\left(\frac{C_{j}\left(s^{0}\right)}{C_{i}\left(s^{0}\right)}\right)^{\gamma_{1}}$.

\section{The underlying demand system}

The Lagrangian for the cost-minimization consumption allocation problem is

$$
\begin{aligned}
L= & \int_{0}^{a_{1}} p_{1,1}(\omega) c_{1,1}(\omega)+\int_{a_{1}}^{a_{2}} p_{1,2}(\omega) c_{1,2}(\omega)+\int_{a_{2}}^{1} p_{1,3}(\omega) c_{1,3}(\omega) \\
& +\lambda\left[C_{1}-\left[\left(d_{1,1}\right)^{\frac{1}{\mu}}\left(C_{1,1}\right)^{\left(\frac{\mu-1}{\mu}\right)}+\left(d_{1,2}\right)^{\frac{1}{\mu}}\left(C_{1,2}\right)^{\left(\frac{\mu-1}{\mu}\right)}+\left(d_{1,3}\right)^{\frac{1}{\mu}}\left(C_{1,3}\right)^{\left(\frac{\mu-1}{\mu}\right)}\right]^{\frac{\mu}{\mu-1}}\right],
\end{aligned}
$$

with first-order conditions for optimality

$$
\begin{aligned}
\frac{\partial L}{\partial c_{1,1}(\omega)} & =p_{1,1}(\omega)-\lambda\left(d_{1,1}\right)^{\frac{1}{\mu}}\left(\frac{1}{a_{1}}\right)^{\frac{1}{\sigma}}\left(\frac{C_{1}}{C_{1,1}}\right)^{\frac{1}{\mu}}\left(\frac{C_{1,1}}{c_{1,1}(\omega)}\right)^{\frac{1}{\sigma}}=0 \\
\frac{\partial L}{\partial c_{1,2}(\omega)} & =p_{1,2}(\omega)-\lambda\left(d_{1,2}\right)^{\frac{1}{\mu}}\left(\frac{1}{a_{2}-a_{1}}\right)^{\frac{1}{\sigma}}\left(\frac{C_{1}}{C_{1,2}}\right)^{\frac{1}{\mu}}\left(\frac{C_{1,2}}{c_{1,2}(\omega)}\right)^{\frac{1}{\sigma}}=0 \\
\frac{\partial L}{\partial c_{1,3}(\omega)} & =p_{1,3}(\omega)-\lambda\left(d_{1,3}\right)^{\frac{1}{\mu}}\left(\frac{1}{1-a_{2}}\right)^{\frac{1}{\sigma}}\left(\frac{C_{1}}{C_{1,3}}\right)^{\frac{1}{\mu}}\left(\frac{C_{1,3}}{c_{1,3}(\omega)}\right)^{\frac{1}{\sigma}}=0 .
\end{aligned}
$$

Take ratios of the prices $p_{1,1}(\omega)$ and $p_{1,1}\left(\omega^{\prime}\right)$,

$$
\frac{p_{1,1}(\omega)}{p_{1,1}\left(\omega^{\prime}\right)}=\left(\frac{c_{1,1}\left(\omega^{\prime}\right)}{c_{1,1}(\omega)}\right)^{\frac{1}{\sigma}} .
$$

Solve for

$$
c_{1,1}(\omega)=c_{1,1}\left(\omega^{\prime}\right)\left(\frac{p_{1,1}\left(\omega^{\prime}\right)}{p_{1,1}(\omega)}\right)^{\sigma} .
$$

Substitute this into the definition of

$$
\begin{aligned}
C_{1,1} & =\left(\frac{1}{a_{1}}\right)^{\frac{1}{\sigma-1}}\left(\int_{0}^{a_{1}} c_{1,1}(\omega)^{\frac{\sigma-1}{\sigma}} d \omega\right)^{\frac{\sigma}{\sigma-1}} \\
& =\left(\frac{1}{a_{1}}\right)^{\frac{1}{\sigma-1}}\left(\int_{0}^{a_{1}}\left(c_{1,1}\left(\omega^{\prime}\right)\left(\frac{p_{1,1}\left(\omega^{\prime}\right)}{p_{1,1}(\omega)}\right)^{\sigma}\right)^{\frac{\sigma-1}{\sigma}} d \omega\right)^{\frac{\sigma}{\sigma-1}} \\
& =\left(\frac{1}{a_{1}}\right)^{\frac{1}{\sigma-1}}\left(c_{1,1}\left(\omega^{\prime}\right)^{\frac{\sigma-1}{\sigma}} p_{1,1}\left(\omega^{\prime}\right)^{(\sigma-1)} \int_{0}^{a_{1}}\left(p_{1,1}(\omega)^{(1-\sigma)}\right) d \omega\right)^{\frac{\sigma}{\sigma-1}} \\
& =c_{1,1}\left(\omega^{\prime}\right) p_{1,1}\left(\omega^{\prime}\right)^{\sigma}\left(\frac{1}{a_{1}}\right)^{\frac{1}{\sigma-1}}\left(\int_{0}^{a_{1}} p_{1,1}(\omega)^{(1-\sigma)} d \omega\right)^{\left(\frac{\sigma}{\sigma-1}\right)} \\
& =c_{1,1}\left(\omega^{\prime}\right) p_{1,1}\left(\omega^{\prime}\right)^{\sigma}\left(\left(\frac{1}{a_{1}}\right)^{\frac{1}{\sigma}} \int_{0}^{a_{1}} p_{1,1}(\omega)^{(1-\sigma)} d \omega\right)^{\left(\frac{\sigma}{\sigma-1}\right)}
\end{aligned}
$$


and now solve for

$$
c_{1,1}\left(\omega^{\prime}\right)=\frac{C_{1,1}}{p_{1,1}\left(\omega^{\prime}\right)^{\sigma}\left(\left(\frac{1}{a_{1}}\right)^{\frac{1}{\sigma}} \int_{0}^{a_{1}} p_{1,1}(\omega)^{(1-\sigma)} d \omega\right)^{\left(\frac{\sigma}{\sigma-1}\right)}}
$$

Substitute (66) into the expenditures for country 1 goods

$$
\begin{aligned}
P_{1,1} C_{1,1} & =\int_{0}^{a_{1}} p_{1,1}(\omega) c_{1,1}(\omega) \\
& =\int_{0}^{a_{1}} p_{1,1}(\omega)\left(\frac{C_{1,1}}{p_{1,1}(\omega)^{\sigma}\left(\left(\frac{1}{a_{1}}\right)^{\frac{1}{\sigma}} \int_{0}^{a_{1}} p_{1,1}\left(\omega^{\prime}\right)^{(1-\sigma)} d \omega^{\prime}\right)^{\left(\frac{\sigma}{\sigma-1}\right)}}\right) d \omega \\
& =\frac{C_{1,1}\left(\int_{0}^{a_{1}} p_{1,1}(\omega)^{(1-\sigma)} d \omega\right)}{\left(\left(\frac{1}{a_{1}}\right)^{\frac{1}{\sigma}} \int_{0}^{a_{1}} p_{1,1}\left(\omega^{\prime}\right)^{(1-\sigma)} d \omega^{\prime}\right)^{\left(\frac{\sigma}{\sigma-1}\right)}}
\end{aligned}
$$

Cancel out the $C_{1,1}$ on both sides,

$$
\begin{aligned}
P_{1,1} & =\frac{\left(\int_{0}^{a_{1}} p_{1,1}(\omega)^{(1-\sigma)} d \omega\right)}{\left(\left(\frac{1}{a_{1}}\right)^{\frac{1}{\sigma}} \int_{0}^{a_{1}} p_{1,1}\left(\omega^{\prime}\right)^{(1-\sigma)} d \omega^{\prime}\right)^{\left(\frac{\sigma}{\sigma-1}\right)}} \\
& =\frac{A}{\left(\left(\frac{1}{a_{1}}\right)^{\frac{1}{\sigma}} A\right)^{\frac{\sigma}{\sigma-1}}}=\frac{A^{1-\frac{\sigma}{\sigma-1}}}{\left(\frac{1}{a_{1}}\right)^{\frac{1}{\sigma} \frac{\sigma}{\sigma-1}}}=\frac{A^{\frac{-1}{\sigma-1}}}{\left(\frac{1}{a_{1}}\right)^{\frac{1}{\sigma-1}}} \\
& =\left(\frac{1}{a_{1}} \int_{0}^{a_{1}} p_{1,1}(\omega)^{(1-\sigma)} d \omega\right)^{\frac{1}{1-\sigma}} .
\end{aligned}
$$

By symmetric arguments, obtain

$$
\begin{gathered}
c_{1,2}\left(\omega^{\prime}\right)=\frac{C_{1,2}}{p_{1,2}\left(\omega^{\prime}\right)^{\sigma}\left(\left(\frac{1}{a_{2}-a_{1}}\right)^{\frac{1}{\sigma}} \int_{a_{1}}^{a_{2}} p_{1,2}(\omega)^{(1-\sigma)} d \omega\right)^{\left(\frac{\sigma}{\sigma-1}\right)}} \\
c_{1,3}\left(\omega^{\prime}\right)=\frac{C_{1,3}}{p_{1,3}\left(\omega^{\prime}\right)^{\sigma}\left(\left(\frac{1}{1-a_{2}}\right)^{\frac{1}{\sigma}} \int_{a_{2}}^{1} p_{1,3}(\omega)^{(1-\sigma)} d \omega\right)^{\left(\frac{\sigma}{\sigma-1}\right)}} \\
P_{1,2}=\left(\frac{1}{a_{2}-a_{1}} \int_{a_{1}}^{a_{2}} p_{1,2}(\omega)^{(1-\sigma)} d \omega\right)^{\frac{1}{1-\sigma}} \\
P_{1,3}=\left(\frac{1}{1-a_{2}} \int_{a_{2}}^{1} p_{1,3}(\omega)^{(1-\sigma)} d \omega\right)^{\frac{1}{1-\sigma}}
\end{gathered}
$$

Next, we obtain the demand functions (18). We work through the case for Country 1. Derivations for Countries 2 and 3 are analogous. If utility is the CES index of composite goods

$$
C_{1}=\left[\left(d_{1,1}\right)^{\frac{1}{\mu}}\left(C_{1,1}\right)^{\left(\frac{\mu-1}{\mu}\right)}+\left(d_{1,2}\right)^{\frac{1}{\mu}}\left(C_{1,2}\right)^{\left(\frac{\mu-1}{\mu}\right)}+\left(d_{1,3}\right)^{\frac{1}{\mu}}\left(C_{1,3}\right)^{\left(\frac{\mu-1}{\mu}\right)}\right]^{\frac{\mu}{\mu-1}}
$$


it's well-known (e.g., Varian, p95, ed 1) the demand functions for the composite goods are

$$
\begin{aligned}
& C_{1,1}=d_{1,1}\left(\frac{P_{1,1}}{P_{1}}\right)^{-\mu} C_{1} \\
& C_{1,2}=d_{1,2}\left(\frac{P_{1,2}}{P_{1}}\right)^{-\mu} C_{1} \\
& C_{1,3}=d_{1,3}\left(\frac{P_{1,3}}{P_{1}}\right)^{-\mu} C_{1}
\end{aligned}
$$

with price index

$$
P_{1}=\left(d_{1,1} P_{1,1}^{1-\mu}+d_{1,2} P_{1,2}^{1-\mu}+d_{1,3} P_{1,3}^{1-\mu}\right)^{\frac{1}{1=\mu}}
$$

Substitute the expression for the price index $P_{1,1}(67)$ into the demand for $c_{1,1}\left(\omega^{\prime}\right)(66)$,

$$
\begin{aligned}
c_{1,1}\left(\omega^{\prime}\right) & =\frac{C_{1,1}}{p_{1,1}\left(\omega^{\prime}\right)^{\sigma}\left(\left(\frac{1}{a_{1}}\right)^{\frac{1}{\sigma}} \int_{0}^{a_{1}} p_{1,1}(\omega)^{(1-\sigma)} d \omega\right)^{\left(\frac{\sigma}{\sigma-1}\right)}} \\
& =\frac{C_{1,1}}{p_{1,1}\left(\omega^{\prime}\right)^{\sigma}\left(a_{1}\right)\left(P_{1,1}\right)^{-\sigma}} \\
& =\left(\frac{p_{1,1}\left(\omega^{\prime}\right)}{P_{1,1}}\right)^{-\sigma} \frac{C_{1,1}}{a_{1}}
\end{aligned}
$$

Now use the expression for the demand for the composite good $C_{11}(68)$ to obtain the individual good $\omega$ demand

$$
c_{1,1}(\omega)=\frac{d_{1,1}}{a_{1}}\left(\frac{p_{1,1}(\omega)}{P_{1,1}}\right)^{-\sigma}\left(\frac{P_{1,1}}{P_{1}}\right)^{-\mu} C_{1}
$$

This is eq. (18) in the text. Analogous steps deliver

$$
\begin{aligned}
c_{1,2}(\omega) & =\frac{d_{1,2}}{a_{2}-a_{1}}\left(\frac{p_{1,2}(\omega)}{P_{1,2}}\right)^{-\sigma}\left(\frac{P_{1,2}}{P_{1}}\right)^{-\mu} C_{1} \\
c_{1,3}(\omega) & =\frac{d_{1,3}}{1-a_{2}}\left(\frac{p_{1,3}(\omega)}{P_{1,3}}\right)^{-\sigma}\left(\frac{P_{1,3}}{P_{1}}\right)^{-\mu} C_{1}
\end{aligned}
$$

\section{Country 1 Firm's Problem}

We solve the problem facing Country 1 firms. Analogous steps are used to obtain solutions for Country 2 and 3 firms. Firm $\omega$ has access to the technology

$$
y_{1, t}(\omega)=A_{1, t} n_{1, t}(\omega) .
$$

The firm's output $y_{1, t}(\omega)$ is demand determined,

$$
y_{1, t}(\omega)=\underbrace{c_{1,1, t}(\omega)}_{1 \text { 's demand }}+\underbrace{c_{2,1, t}(\omega)}_{\text {2's demand }}+\underbrace{c_{3,1, t}(\omega)}_{\text {3's demand }} .
$$

We can write the firm's nominal revenues, in Country 1 currency units, as

$$
\text { Revenues }=p_{1,1, t}(\omega) c_{1,1, t}(\omega)+e_{1,2, t} p_{2,1, t}(\omega) c_{2,1, t}(\omega)+e_{1,3, t} p_{3,1, t}(\omega)
$$


Under this linear technology that depends only on labor, the firm's marginal cost function is a constant. The cost of one more worker is $W_{1} / P_{1}$. That worker produces $A_{1}$ units of output so the unit marginal cost (the cost of making one more unit of output) is $\frac{W_{1, t}}{A_{1, t} P_{1, t}}$. Hence, real profits are

$$
\begin{aligned}
\Pi_{1, t}= & \frac{e_{1,1, t}}{P_{1, t}} p_{1,1, t}(\omega) c_{1,1, t}(\omega)+\frac{e_{1,2, t}}{P_{1, t}} p_{2,1, t}(\omega) c_{2,1, t}(\omega)+\frac{e_{1,3, t}}{P_{1, t}} p_{3,1, t}(\omega)-\frac{W_{1, t}}{P_{1, t}} n_{1, t}(\omega) \\
= & \frac{e_{1,1, t}}{P_{1, t}} p_{1,1, t}(\omega) c_{1,1, t}(\omega)+\frac{e_{1,2, t}}{P_{1, t}} p_{2,1, t}(\omega) c_{2,1, t}(\omega)+\frac{e_{1,3, t}}{P_{1, t}} p_{3,1, t}(\omega) \\
& -\frac{W_{1, t}}{P_{1, t}} \frac{\left(c_{1,1, t}(\omega)+c_{2,1, t}(\omega)+c_{3,1, t}(\omega)\right)}{A_{1, t}}
\end{aligned}
$$

Substitute the demand formulations (18) into the preceding to express time $t+k$ profits as

$$
\begin{aligned}
\Pi_{t+k}(\omega)= & \frac{e_{1,1, t+k}}{P_{1, t+k}} p_{1,1, t+k}(\omega) \phi_{1,1, t+k}\left(\frac{p_{1,1, t+k}(\omega)}{P_{1,1, t+k}}\right)^{-\sigma} C_{1, t+k} \\
& -\frac{W_{1, t+k}}{A_{1, t+k} P_{1, t+k}} \phi_{1,1, t+k}\left(\frac{p_{1,1, t+k}(\omega)}{P_{1,1, t+k}}\right)^{-\sigma} C_{1, t+k} \\
& +\frac{e_{1,2, t+k}}{P_{1, t+k}} p_{2,1, t+k}(\omega) \phi_{2,1, t+k}\left(\frac{p_{2,1, t+k}(\omega)}{P_{2,1, t+k}}\right)^{-\sigma} C_{2, t+k} \\
& -\frac{W_{1, t+k}}{A_{1, t+k} P_{1, t+k}} \phi_{2,1, t+k}\left(\frac{p_{2,1, t+k}(\omega)}{P_{2,1, t+k}}\right)^{-\sigma} C_{2, t+k} \\
& +\frac{e_{1,3, t+k}}{P_{1, t+k}} p_{3,1, t+k}(\omega) \phi_{3,1, t+k}\left(\frac{p_{3,1, t+k}(\omega)}{P_{3,1, t+k}}\right)^{-\sigma} C_{3, t+k} \\
& -\frac{W_{1, t+k}}{A_{1, t+k} P_{1, t+k}} \phi_{3,1, t+k}\left(\frac{p_{3,1, t+k}(\omega)}{P_{3,1, t+k}}\right)^{-\sigma} C_{3, t+k}
\end{aligned}
$$

Calvo pricing. Firms are subject to Calvo pricing. $\alpha$ is the probability that the firm is stuck with last period's price, $(1-\alpha)$ is the probability that the firm can reset its price. We allow reset probabilities to vary across countries with $\alpha_{1}, \alpha_{2}$ and $\alpha_{3}$ in countries 1,2 , and 3 , respectively. The firm waits to see if it is chosen to reset prices for products sent to country $j$. If chosen to reset prices in country 1 , the expected present value of future profits from that price resetting decision is

$$
\begin{aligned}
& E_{t} \sum_{k=0}^{\infty}\left(\alpha_{1} \beta\right)^{k} C_{1, t+k}^{-\gamma_{1}}\left(\begin{array}{c}
\frac{e_{1,1, t+k}}{P_{1, t+k}} p_{1,1, t}^{*}(\omega) \phi_{1,1, t+k}\left(\frac{p_{1,1, t}^{*}(\omega)}{P_{1,1, t+k}}\right)^{-\sigma} C_{1, t+k} \\
-\frac{W_{1, t+k}}{A_{1, t+k} P_{1, t+k}} \phi_{1,1, t+k}\left(\frac{p_{1,1, t}(\omega)}{P_{1,1, t+k}}\right)^{-\sigma} C_{1, t+k}
\end{array}\right) \\
= & E_{t} \sum_{k=0}^{\infty}\left(\alpha_{1} \beta\right)^{k} C_{1, t+k}^{1-\gamma_{1}} \phi_{1,1, t+k} P_{1,1, t+k}^{\sigma}\left(\begin{array}{c}
\frac{e_{1,1, t+k}}{P_{1, t+k}} p_{1,1, t}^{*}(\omega)^{1-\sigma} \\
-\frac{W_{1, t+k}}{A_{1, t+k} P_{1, t+k}} p_{1,1, t}^{*}(\omega)^{-\sigma}
\end{array}\right)
\end{aligned}
$$

For country 2 price reset,

$$
\begin{aligned}
& E_{t} \sum_{k=0}^{\infty}\left(\alpha_{2} \beta\right)^{k} C_{1, t+k}^{-\gamma_{1}}\left(\begin{array}{c}
\frac{e_{1,2, t+k}}{P_{1, t+k}} p_{2,1, t}^{*}(\omega) \phi_{2,1, t+k}\left(\frac{p_{2,1, t}^{*}(\omega)}{P_{2,1, t+k}}\right)^{-\sigma} C_{2, t+k} \\
-\frac{W_{1, t+k}}{A_{1, t+k} P_{1, t+k}} \phi_{2,1, t+k}\left(\frac{p_{2,1, t}(\omega)}{P_{2,1, t+k}}\right)^{-\sigma} C_{2, t+k}
\end{array}\right) \\
= & E_{t} \sum_{k=0}^{\infty}\left(\alpha_{2} \beta\right)^{k} C_{2, t+k} C_{1, t+k}^{-\gamma_{1}} \phi_{2,1, t+k} P_{2,1, t+k}^{\sigma}\left(\begin{array}{c}
\frac{e_{1,2, t+k}}{P_{1, t+k}^{*}} p_{2,1, t}^{*}(\omega)^{1-\sigma} \\
-\frac{W_{1, t+k}}{A_{1, t+k} P_{1, t+k}} p_{2,1, t}^{*}(\omega)^{-\sigma}
\end{array}\right)
\end{aligned}
$$


and for country 3 price reset,

$$
\begin{aligned}
& E_{t} \sum_{k=0}^{\infty}\left(\alpha_{3} \beta\right)^{k} C_{1, t+k}^{-\gamma_{1}}\left(\begin{array}{c}
\frac{e_{1,3, t+k}}{P_{1, t+k}} p_{3,1, t}^{*}(j) \phi_{3,1, t+k}\left(\frac{p_{3,1, t}^{*}(j)}{P_{3,1, t+k}}\right)^{-\sigma} C_{2, t+k} \\
-\frac{W_{1, t+k}}{A_{1, t+k} P_{1, t+k}} \phi_{3,1, t+k}\left(\frac{p_{3,1, t}^{*}(j)}{P_{3,1, t+k}}\right)^{-\sigma} C_{3, t+k}
\end{array}\right) \\
= & E_{t} \sum_{k=0}^{\infty}\left(\alpha_{3} \beta\right)^{k} C_{3, t+k} C_{1, t+k}^{-\gamma_{1}} \phi_{3,1, t+k} P_{3,1, t+k}^{\sigma}\left(\begin{array}{c}
\frac{e_{1,3, t+k}}{P_{1, t+k}} p_{3,1, t}^{*}(j)^{1-\sigma} \\
-\frac{W 1, t+k}{A_{1, t+k} P_{1, t+k}} p_{3,1, t}^{*}(j)^{-\sigma}
\end{array}\right)
\end{aligned}
$$

\section{Illustrate price reset by Country 1 firms}

To fix ideas, we'll look at the firm's decision to reset prices on exports to Country 3. Differentiate (69) with respect to $p_{3,1, t}^{*}(w)$ and set result to 0 to obtain

$$
0=E_{t} \sum_{k=0}^{\infty}\left(\alpha_{3} \beta\right)^{k} C_{3, t+k} C_{1, t+k}^{-\gamma_{1}} \phi_{3,1, t+k} P_{3,1, t+k}^{\sigma}\left(\begin{array}{c}
(1-\sigma) \frac{e_{1,3, t+k}}{P_{1, t+k}} p_{3,1, t}^{*}(j)^{-\sigma} \\
+\sigma \frac{W_{1, t+k}}{A_{1, t+k} P_{1, t+k}} p_{3,1, t}^{*}(j)^{-\sigma-1}
\end{array}\right),
$$

which rearranges to

$$
\begin{aligned}
& p_{3,1, t}^{*}\left(E_{t} \sum_{k=0}^{\infty}\left(\alpha_{3} \beta\right)^{k} C_{3, t+k} C_{1, t+k}^{-\gamma_{1}} \phi_{3,1, t+k} P_{3,1, t+k}^{\sigma} \frac{e_{1,3, t+k}}{P_{1, t+k}}\right) \\
= & \frac{\sigma}{(\sigma-1)}\left(E_{t} \sum_{k=0}^{\infty}\left(\alpha_{3} \beta\right)^{k} C_{3, t+k} C_{1, t+k}^{-\gamma_{1}} \phi_{3,1, t+k} P_{3,1, t+k}^{\sigma} \frac{W_{1, t+k}}{A_{1, t+k} P_{1, t+k}}\right) .
\end{aligned}
$$

Call the left hand side of eq.(70) lhs. Then,

$$
\begin{aligned}
l h s & =p_{3,1, t}^{*}\left(E_{t} \sum_{k=0}^{\infty}\left(\alpha_{3} \beta\right)^{k} C_{3, t+k} C_{1, t+k}^{-\gamma_{1}} \phi_{3,1, t+k} P_{3,1, t+k}^{\sigma} \frac{e_{1,3, t+k}}{P_{1, t+k}}\right) \\
& =p_{3,1, t}^{*}\left(E_{t} \sum_{k=0}^{\infty}\left(\alpha_{3} \beta\right)^{k} C_{3, t+k} C_{1, t+k}^{-\gamma_{1}} \phi_{3,1, t+k} P_{3,1, t+k}^{\sigma} \frac{e_{1,3, t+k}}{P_{1, t+k}}\left(\frac{P_{3,1, t+k}}{P_{3,1, t+k}} \frac{P_{3, t+k}}{P_{3, t+k}}\right)\right) \\
& =p_{3,1, t}^{*}\left(E_{t} \sum_{k=0}^{\infty}\left(\alpha_{3} \beta\right)^{k} C_{3, t+k} C_{1, t+k}^{-\gamma_{1}} \phi_{3,1, t+k} P_{3,1, t+k}^{\sigma-1} \frac{P_{3, t+k} e_{1,3, t+k}}{P_{1, t+k}}\left(\frac{P_{3,1, t+k}}{P_{3, t+k}}\right)\right) \\
& =p_{3,1, t}^{*}\left(E_{t} \sum_{k=0}^{\infty}\left(\alpha_{3} \beta\right)^{k} C_{3, t+k} C_{1, t+k}^{-\gamma_{1}} \phi_{3,1, t+k} P_{3,1, t+k}^{\sigma-1}\left(\frac{P_{3,1, t+k}}{P_{3, t+k}}\right) q_{1,3, t+k}\right)
\end{aligned}
$$

Put this back together with the right hand side of eq. (70),

$$
\begin{aligned}
& p_{3,1, t}^{*}\left(E_{t} \sum_{k=0}^{\infty}\left(\alpha_{3} \beta\right)^{k} C_{3, t+k} C_{1, t+k}^{-\gamma_{1}} \phi_{3,1, t+k} P_{3,1, t+k}^{\sigma-1}\left(\frac{P_{3,1, t+k}}{P_{3, t+k}}\right) q_{1,3, t+k}\right) \\
= & \frac{\sigma}{(\sigma-1)}\left(E_{t} \sum_{k=0}^{\infty}\left(\alpha_{3} \beta\right)^{k} C_{3, t+k} C_{1, t+k}^{-\gamma_{1}} \phi_{3,1, t+k} P_{3,1, t+k}^{\sigma} \frac{W_{1, t+k}}{A_{1, t+k} P_{1, t+k}}\right)
\end{aligned}
$$


Multiply both sides by $P_{3,1, t}^{-\sigma}$ :

$$
\begin{aligned}
& p_{3,1, t}^{*} P_{3,1, t}^{-\sigma}\left(E_{t} \sum_{k=0}^{\infty}\left(\alpha_{3} \beta\right)^{k} C_{3, t+k} C_{1, t+k}^{-\gamma_{1}} \phi_{3,1, t+k} P_{3,1, t+k}^{\sigma-1}\left(\frac{P_{3,1, t+k}}{P_{3, t+k}}\right) q_{1,3, t+k}\right) \\
= & \frac{\sigma}{(\sigma-1)} P_{3,1, t}^{-\sigma}\left(E_{t} \sum_{k=0}^{\infty}\left(\alpha_{3} \beta\right)^{k} C_{3, t+k} C_{1, t+k}^{-\gamma_{1}} \phi_{3,1, t+k} P_{3,1, t+k}^{\sigma} \frac{W_{1, t+k}}{A_{1, t+k} P_{1, t+k}}\right)
\end{aligned}
$$

Multiply and divide the left hand side by $P_{3,1, t}$

$$
\begin{aligned}
& p_{3,1, t}^{*} P_{3,1, t}^{-\sigma}\left(\frac{P_{3,1, t}}{P_{3,1, t}}\right)\left(E_{t} \sum_{k=0}^{\infty}\left(\alpha_{3} \beta\right)^{k} C_{3, t+k} C_{1, t+k}^{-\gamma_{1}} \phi_{3,1, t+k} P_{3,1, t+k}^{\sigma-1}\left(\frac{P_{3,1, t+k}}{P_{3, t+k}}\right) q_{1,3, t+k}\right) \\
= & \frac{\sigma}{(\sigma-1)} P_{3,1, t}^{-\sigma}\left(E_{t} \sum_{k=0}^{\infty}\left(\alpha_{3} \beta\right)^{k} C_{3, t+k} C_{1, t+k}^{-\gamma_{1}} \phi_{3,1, t+k} P_{3,1, t+k}^{\sigma} \frac{W_{1, t+k}}{A_{1, t+k} P_{1, t+k}}\right) \\
& \frac{p_{3,1, t}^{*}}{P_{3,1, t}}\left(E_{t} \sum_{k=0}^{\infty}\left(\alpha_{3} \beta\right)^{k} C_{3, t+k} C_{1, t+k}^{-\gamma_{1}} \phi_{3,1, t+k}\left(\frac{P_{3,1, t+k}}{P_{3,1, t}}\right)^{\sigma-1}\left(\frac{P_{3,1, t+k}}{P_{3, t+k}}\right) q_{1,3, t+k}\right) \\
= & \frac{\sigma}{(\sigma-1)}\left(E_{t} \sum_{k=0}^{\infty}\left(\alpha_{3} \beta\right)^{k} C_{3, t+k} C_{1, t+k}^{-\gamma_{1}} \phi_{3,1, t+k}\left(\frac{P_{3,1, t+k}}{P_{3,1, t}}\right)^{\sigma} \frac{W_{1, t+k}}{A_{1, t+k} P_{1, t+k}}\right)
\end{aligned}
$$

To lighten the notation, define $F_{3,1, t}=\frac{p_{3,1, t}^{*}}{P_{3,1, t}}$. This gives

$$
\begin{aligned}
& F_{3,1, t}\left(E_{t} \sum_{k=0}^{\infty}\left(\alpha_{3} \beta\right)^{k} C_{3, t+k} C_{1, t+k}^{-\gamma_{1}} \phi_{3,1, t+k}\left(\frac{P_{3,1, t+k}}{P_{3,1, t}}\right)^{\sigma-1}\left(\frac{P_{3,1, t+k}}{P_{3, t+k}}\right) q_{1,3, t+k}\right) \\
= & \frac{\sigma}{(\sigma-1)}\left(E_{t} \sum_{k=0}^{\infty}\left(\alpha_{3} \beta\right)^{k} C_{3, t+k} C_{1, t+k}^{-\gamma_{1}} \phi_{3,1, t+k}\left(\frac{P_{3,1, t+k}}{P_{3,1, t}}\right)^{\sigma} \frac{W_{1, t+k}}{A_{1, t+k} P_{1, t+k}}\right)
\end{aligned}
$$

\section{Steady State}

In the steady state, for Countries $j=1,2,3$,

$$
\begin{aligned}
& A_{j}=1 \\
& P_{j}=P_{j, 1}=P_{j, 2}=P_{j, 3}=p_{j, 1}(\omega)=p_{j, 2}(\omega)=p_{j, 3}(\omega) \\
& i_{j}=\delta \\
& Y_{j}=C_{j}=n_{j} \\
& C_{j, k}=d_{j, k} C_{j}=d_{j, k} n_{j} \\
& \frac{W_{j}}{P_{j}}=\theta_{2}\left(1-n_{j}\right)^{-\gamma_{2}}\left(n_{j}\right)^{\gamma_{1}} \\
&\left(\frac{M_{j}}{P_{j}}\right)^{-\gamma_{3}}=\frac{\delta}{1+\delta} \frac{\left(n_{j}\right)^{-\gamma_{1}}}{\theta_{3}}
\end{aligned}
$$


The real exchange rate

$$
q_{i, j}=\left(\frac{C_{j}}{C_{i}}\right)^{-\gamma_{1}}\left(q_{i, j, 0}\left(\frac{C_{i, 0}}{C_{j, 0}}\right)^{-\gamma_{1}}\right)=\left(\frac{Y_{j}}{Y_{i}}\right)^{-\gamma_{1}}\left(q_{0}\left(\frac{Y_{i, 0}}{Y_{j, 0}}\right)^{-\gamma_{1}}\right)
$$

depends on initial conditions. We assume $\left(q_{0}\left(\frac{Y_{i, 0}}{Y_{j, 0}}\right)^{-\gamma_{1}}\right)=1$. Hence, with equal sized countries, the steady state value of the real exchange rate is 1.

The steady-state price of any good in units of the home currency is,

$$
p_{i, j}^{*}\left(\frac{e_{j, i}}{P_{j}}\right)=\frac{\sigma}{(\sigma-1)}\left(\frac{W_{j}}{P_{j}}\right)
$$

which is a constant markup over nominal marginal cost. Since all firms in Country $j$ will charge the same steady-state price on goods destined for Country $i$, we have

$$
\left(\frac{W_{j}}{A_{j} P_{j}}\right)=\left(\frac{e_{j, 3} p_{3, j}^{*}}{P_{j}}\right) \frac{(\sigma-1)}{\sigma}=\left(\frac{e_{j, 2} p_{2, j}^{*}}{P_{j}}\right) \frac{(\sigma-1)}{\sigma}=\left(\frac{p_{j, j}^{*}}{P_{j}}\right) \frac{(\sigma-1)}{\sigma} .
$$

This implies all countries have identical steady-state marginal cost

$$
\left(\frac{W_{i}}{A_{i} P_{i}}\right)=\frac{(\sigma-1)}{\sigma} .
$$

\section{First-order approximation around the steady state}

We omit the steps to obtain the first-order approximations of the household's Euler equations since they have been presented in the literature and the steps are straightforward. We provide more details on the steps to approximate the price-reset decisions by firms. The notation here is to use a hat to denote the $\log$ approximate deviation from the steady state, so if $x$ is the steady state value of $x_{t}$, we write $\hat{x}_{t}=\frac{\left(x_{t}-x\right)}{x}$. In obtaining the approximation, we will exploit two results.

Result 1. The first result is just the equivalence between a forward-looking first-order stochastic difference equation and its present value formulation,

$$
x_{t}=(1-\beta) E_{t} \sum_{k=0} \beta^{k} y_{t+k}=(1-\beta) y_{t}+\beta E_{t} x_{t+1} .
$$

Result 2.

$$
\hat{F}_{3,1, t}=\frac{\alpha_{3}}{1-\alpha_{3}} \pi_{3,1, t}
$$

To obtain this result, since $F_{3,1, t}=\frac{p_{3,1, t}^{*}}{P_{3,1, t}}$, it follows that

$$
\hat{F}_{3,1, t}=\hat{p}_{3,1, t}^{*}-\hat{P}_{3,1, t}
$$


Notice that

$$
\begin{aligned}
P_{3,1, t}^{1-\sigma} & =\alpha P_{3,1, t-1}^{1-\sigma}+(1-\alpha) p_{3,1, t}^{*(1-\sigma)} \\
(1-\sigma) P_{3,1}^{1-\sigma} \hat{P}_{3,1, t} & =\alpha(1-\sigma) P_{3,1}^{1-\sigma} \hat{P}_{3,1, t-1}+(1-\alpha)(1-\sigma) p_{3,1}^{*} \hat{p}_{3,1, t}^{*} \\
\hat{P}_{3,1, t} & =\alpha \hat{P}_{3,1, t-1}+(1-\alpha) \hat{p}_{3,1, t}^{*} \\
(1-\alpha) \hat{p}_{3,1, t}^{*} & =\hat{P}_{3,1, t}-\alpha \hat{P}_{3,1, t-1}+\alpha \hat{P}_{3,1, t}-\alpha \hat{P}_{3,1, t} \\
& =(1-\alpha) \hat{P}_{3,1, t}+\alpha \pi_{3,1, t} \\
\hat{p}_{3,1, t}^{*}-\hat{P}_{3,1, t} & =\frac{\alpha}{1-\alpha} \pi_{3,1, t}
\end{aligned}
$$

The result is then obtained by substituting this last line into (73).

To obtain the approximation for eq. (71) around the steady state, recall that

$$
\begin{aligned}
\phi_{i, 1, t} & =\left(\frac{d_{i, 1}}{a_{1}}\right)\left(\frac{P_{i, 1, t}}{P_{i, t}}\right)^{-\mu} \\
\phi_{i, 2, t} & =\left(\frac{d_{i, 2}}{a_{2}-a_{1}}\right)\left(\frac{P_{i, 2, t}}{P_{i, t}}\right)^{-\mu}, \\
\phi_{i, 3, t} & =\left(\frac{d_{i, 3}}{1-a_{2}}\right)\left(\frac{P_{i, 3, t}}{P_{i . t}}\right)^{-\mu} .
\end{aligned}
$$

Substitute these expressions into eq. (71) to obtain

$$
\begin{aligned}
& F_{3,1, t}\left(E_{t} \sum_{k=0}^{\infty}\left(\alpha_{3} \beta\right)^{k} C_{3, t+k} C_{1, t+k}^{-\gamma_{1}} \phi_{3,1, t+k}\left(\frac{P_{3,1, t+k}}{P_{3,1, t}}\right)^{\sigma-1}\left(\frac{P_{3,1, t+k}}{P_{3, t+k}}\right) q_{1,3, t+k}\right) \\
= & \frac{\sigma}{(\sigma-1)}\left(E_{t} \sum_{k=0}^{\infty}\left(\alpha_{3} \beta\right)^{k} C_{3, t+k} C_{1, t+k}^{-\gamma_{1}} \phi_{3,1, t+k}\left(\frac{P_{3,1, t+k}}{P_{3,1, t}}\right)^{\sigma} \frac{W_{1, t+k}}{A_{1, t+k} P_{1, t+k}}\right) .
\end{aligned}
$$

Beginning with a typical term on the left hand side,

$$
\begin{gathered}
C_{3, t+k} C_{1, t+k}^{-\gamma_{1}} \phi_{3,1, t+k}\left(\frac{P_{3,1, t+k}}{P_{3,1, t}}\right)^{\sigma-1}\left(\frac{P_{3,1, t+k}}{P_{3, t+k}}\right) q_{1,3, t+k} \\
=\left(C_{3} C_{1}^{-\gamma_{1}} \phi_{3,1} q_{1,3}\right)\left(\begin{array}{c}
\hat{q}_{1,3, t+k}+\hat{\phi}_{3,1, t+k}+\hat{C}_{3, t+k}-\gamma_{1} \hat{C}_{1, t+k} \\
+(\sigma-1)\left(\hat{P}_{3,1, t+k}-\hat{P}_{3,1, t}\right) \\
+\left(\hat{P}_{3,1, t+k}-\hat{P}_{3, t+k}\right)
\end{array}\right) \\
=\left(C_{3} C_{1}^{-\gamma_{1}} \phi_{3,1} q_{1,3}\right)\left(\begin{array}{c}
\hat{q}_{1,3, t+k}-\mu\left(\hat{P}_{3,1, t+k}-\hat{P}_{3, t+k}\right)+\hat{C}_{3, t+k}-\gamma_{1} \hat{C}_{1, t+k} \\
+(\sigma-1)\left(\hat{P}_{3,1, t+k}-\hat{P}_{3,1, t}\right)+\left(\hat{P}_{3,1, t+k}-\hat{P}_{3, t+k}\right)
\end{array}\right),
\end{gathered}
$$

where

$$
\hat{\phi}_{i, 1}=-\mu\left(\hat{P}_{i, 1, t}-\hat{P}_{i, t}\right)
$$


A typical term on the right hand side approximates to

$$
\begin{aligned}
& \frac{\sigma}{(\sigma-1)}\left(C_{3, t+k} C_{1, t+k}^{-\gamma_{1}} \phi_{3,1, t+k}\left(\frac{P_{3,1, t+k}}{P_{3,1, t}}\right)^{\sigma} \frac{W_{1, t+k}}{A_{1, t+k} P_{1, t+k}}\right) \\
= & \frac{\sigma}{(\sigma-1)}\left(C_{3, t+k} C_{1, t+k}^{-\gamma_{1}} \phi_{3,1, t+k}\left(\frac{P_{3,1, t+k}}{P_{3,1, t}}\right)^{\sigma} m_{1, t+k}\right) \\
= & \frac{\sigma}{(\sigma-1)}\left(C_{3} C_{1}^{-\gamma_{1}} \phi_{3,1} m_{1}\right)\left(\hat{\phi}_{3,1, t+k}+\hat{C}_{3, t+k}-\gamma_{1} \hat{C}_{1, t+k}+\hat{m}_{1, t+k}+\sigma\left(\hat{P}_{3,1, t+k}-\hat{P}_{3,1, t}\right)\right) \\
= & \frac{\sigma}{(\sigma-1)}\left(C_{3} C_{1}^{-\gamma_{1}} \phi_{3,1} m_{1}\right)\left(\hat{C}_{3, t+k}-\gamma_{1} \hat{C}_{1, t+k}+\hat{m}_{1, t+k}+\sigma\left(\hat{P}_{3,1, t+k}-\hat{P}_{3,1, t}\right)-\mu\left(\hat{P}_{3,1, t+k}-\hat{P}_{3, t+k}\right)\right)
\end{aligned}
$$

Putting them together gives,

$$
\begin{aligned}
& \sum_{k=0}^{\infty}\left(\alpha_{3} \beta\right)^{k}\left(C_{3} C_{1}^{-\gamma_{1}} \phi_{3,1} q_{1,3}\right) \hat{F}_{3,1, t} \\
+ & \left(C_{3} C_{1}^{-\gamma_{1}} \phi_{3,1} q_{1,3}\right) E_{t} \sum_{k=0}^{\infty}\left(\alpha_{3} \beta\right)^{k}\left(\begin{array}{c}
\hat{q}_{1,3, t+k}-\mu\left(\hat{P}_{3,1, t+k}-\hat{P}_{3, t+k}\right)+\hat{C}_{3, t+k}-\gamma_{1} \hat{C}_{1, t+k} \\
+(\sigma-1)\left(\hat{P}_{3,1, t+k}-\hat{P}_{3,1, t}\right)+\left(\hat{P}_{3,1, t+k}-\hat{P}_{3, t+k}\right)
\end{array}\right) \\
= & \frac{\sigma}{(\sigma-1)}\left(C_{3} C_{1}^{-\gamma_{1}} \phi_{3,1} m_{1}\right) E_{t} \sum_{k=0}^{\infty}\left(\alpha_{3} \beta\right)^{k}\left(\begin{array}{c}
\hat{C}_{3, t+k}-\gamma_{1} \hat{C}_{1, t+k}+\hat{m}_{1, t+k} \\
+\sigma\left(\hat{P}_{3,1, t+k}-\hat{P}_{3,1, t}\right)-\mu\left(\hat{P}_{3,1, t+k}-\hat{P}_{3, t+k}\right)
\end{array}\right)
\end{aligned}
$$

To lighten notation, define

$$
\begin{aligned}
b_{q} & =\left(C_{3} C_{1}^{-\gamma_{1}} \phi_{3,1} q_{1,3}\right) \\
b_{m} & =\left(C_{3} C_{1}^{-\gamma_{1}} \phi_{3,1} m_{1}\right) \\
b & =\frac{b_{m}}{b_{q}}=\bar{m}_{1}=\frac{(\sigma-1)}{\sigma} \\
\alpha & =\alpha_{3} \\
(b-1) & =-\frac{1}{\sigma}
\end{aligned}
$$

Then

$$
\begin{aligned}
& \frac{\hat{F}_{3,1, t}}{1-\alpha \beta} \\
& +E_{t} \sum_{k=0}^{\infty}\left(\alpha_{3} \beta\right)^{k}\left(\begin{array}{c}
\hat{q}_{1,3, t+k}-\mu\left(\hat{P}_{3,1, t+k}-\hat{P}_{3, t+k}\right)+\hat{C}_{3, t+k}-\gamma_{1} \hat{C}_{1, t+k} \\
+(\sigma-1)\left(\hat{P}_{3,1, t+k}-\hat{P}_{3,1, t}\right)+\left(\hat{P}_{3,1, t+k}-\hat{P}_{3, t+k}\right)
\end{array}\right) \\
= & \frac{\sigma}{(\sigma-1)} E_{t} b \sum_{k=0}^{\infty}\left(\alpha_{3} \beta\right)^{k}\left(\begin{array}{c}
\hat{C}_{3, t+k}-\gamma_{1} \hat{C}_{1, t+k}+\hat{m}_{1, t+k} \\
+\sigma\left(\hat{P}_{3,1, t+k}-\hat{P}_{3,1, t}\right)-\mu\left(\hat{P}_{3,1, t+k}-\hat{P}_{3, t+k}\right)
\end{array}\right) .
\end{aligned}
$$

Since

$$
\frac{\sigma}{(\sigma-1)} b=1
$$

It follows that, 


$$
\begin{aligned}
& \frac{\hat{F}_{3,1, t}}{1-\alpha \beta}=E_{t} \sum_{k=0}^{\infty}\left(\alpha_{3} \beta\right)^{k}\left(\hat{C}_{3, t+k}-\gamma_{1} \hat{C}_{1, t+k}+\hat{m}_{1, t+k}+\sigma\left(\hat{P}_{3,1, t+k}-\hat{P}_{3,1, t}\right)-\mu\left(\hat{P}_{3,1, t+k}-\hat{P}_{3, t+k}\right)\right) \\
& -\sum_{k=0}^{\infty}\left(\alpha_{3} \beta\right)^{k}\left(\begin{array}{c}
\hat{q}_{1,3, t+k}-\mu\left(\hat{P}_{3,1, t+k}-\hat{P}_{3, t+k}\right)+\hat{C}_{3, t+k}-\gamma_{1} \hat{C}_{1, t+k} \\
+(\sigma-1)\left(\hat{P}_{3,1, t+k}-\hat{P}_{3,1, t}\right)+\left(\hat{P}_{3,1, t+k}-\hat{P}_{3, t+k}\right)
\end{array}\right) \\
& =E_{t} \sum_{k=0}^{\infty}\left(\alpha_{3} \beta\right)^{k}\left(\begin{array}{c}
\hat{C}_{3, t+k}-b \gamma_{1} \hat{C}_{1, t+k}+b \hat{m}_{1, t+k} \\
+\sigma\left(\hat{P}_{3,1, t+k}-\hat{P}_{3,1, t}\right)-\mu\left(\hat{P}_{3,1, t+k}-\hat{P}_{3, t+k}\right) \\
-\left(\begin{array}{c}
\hat{q}_{1,3, t+k}-\mu\left(\hat{P}_{3,1, t+k}-\hat{P}_{3, t+k}\right)+\hat{C}_{3, t+k}-\gamma_{1} \hat{C}_{1, t+k} \\
+(\sigma-1)\left(\hat{P}_{3,1, t+k}-\hat{P}_{3,1, t}\right)+\left(\hat{P}_{3,1, t+k}-\hat{P}_{3, t+k}\right)
\end{array}\right)
\end{array}\right) \\
& =E_{t} \sum_{k=0}^{\infty}\left(\alpha_{3} \beta\right)^{k}\left(\hat{m}_{1, t+k}+\left(\hat{P}_{3,1, t+k}-\hat{P}_{3,1, t}\right)-\hat{q}_{1,3, t+k}-\left(\hat{P}_{3,1, t+k}-\hat{P}_{3, t+k}\right)\right) \\
& =E_{t} \sum_{k=0}^{\infty}\left(\alpha_{3} \beta\right)^{k}\left(\begin{array}{c}
\underbrace{\hat{m}_{1, t+k}-\hat{q}_{1,3, t+k}}_{x_{t+k}} \\
+\hat{P}_{3,1, t+k}-\left(\hat{P}_{3,1, t+k}-\hat{P}_{3, t+k}\right)
\end{array}\right)-\hat{P}_{3,1, t}\left(\sum_{k=0}^{\infty}\left(\alpha_{3} \beta\right)^{k}\right)
\end{aligned}
$$

To lighten notation again, let

$$
x_{t+k}=\hat{m}_{1, t+k}-\hat{q}_{1,3, t+k} .
$$

Then

$$
\begin{gathered}
\frac{\hat{F}_{3,1, t}}{1-\alpha \beta}=E_{t} \sum_{k=0}^{\infty}\left(\alpha_{3} \beta\right)^{k}\left(x_{t+k}+\hat{P}_{3,1, t+k}-\left(\hat{P}_{3,1, t+k}-\hat{P}_{3, t+k}\right)\right) \\
-\frac{1}{1-\alpha \beta} \hat{P}_{3,1, t} \\
\frac{\hat{F}_{3,1, t}+\frac{1}{1-\alpha \beta} \hat{P}_{3,1, t}}{1-\alpha \beta}=E_{t} \sum_{k=0}^{\infty}\left(\alpha_{3} \beta\right)^{k}(x_{t+k}+\underbrace{\hat{P}_{3,1, t+k}-\left(\hat{P}_{3,1, t+k}-\hat{P}_{3, t+k}\right)}_{y_{t+k}}) \\
y_{t+k}=\hat{P}_{3, t+k}
\end{gathered}
$$

Using Results 1 and 2 here gives

$$
\begin{aligned}
\frac{\hat{F}_{3,1, t}}{1-\alpha \beta}+\frac{1}{1-\alpha \beta} \hat{P}_{3,1, t} & =E_{t} \sum_{k=0}^{\infty}\left(\alpha_{3} \beta\right)^{k}\left(x_{t+k}+\hat{P}_{3, t+k}\right) \\
\hat{F}_{3,1, t}+\hat{P}_{3,1, t} & =(1-\alpha \beta) E_{t} \sum_{k=0}^{\infty}(\alpha \beta)^{k}\left(x_{t+k}+\hat{P}_{3, t+k}\right) \\
\frac{\alpha}{1-\alpha} \pi_{3,1, t}+\hat{P}_{3,1, t} & =(1-\alpha \beta)\left(x_{t}+\hat{P}_{3, t}\right)+(\alpha \beta) E_{t}\left(\frac{\alpha}{1-\alpha} \pi_{3,1, t}+\hat{P}_{3,1, t}\right)
\end{aligned}
$$




$$
\begin{aligned}
& \frac{\alpha}{1-\alpha} \pi_{3,1, t}=(1-\alpha \beta)\left(x_{t}+\hat{P}_{3, t}\right)+(\alpha \beta) E_{t}\left(\frac{\alpha}{1-\alpha} \pi_{3,1, t+1}+\hat{P}_{3,1, t+1}\right)-\hat{P}_{3,1, t} \\
& +(\alpha \beta) \hat{P}_{3,1, t}-(\alpha \beta) \hat{P}_{3,1, t} \\
& =(1-\alpha \beta)\left(x_{t}+\hat{P}_{3, t}\right)+(\alpha \beta) E_{t} \frac{\alpha}{1-\alpha} \pi_{3,1, t+1}+(\alpha \beta) E_{t} \hat{P}_{3,1, t+1} \\
& -(\alpha \beta) \hat{P}_{3,1, t}-\left(\hat{P}_{3,1, t}-(\alpha \beta) \hat{P}_{3,1, t}\right) \\
& =(1-\alpha \beta)\left(x_{t}+\hat{P}_{3, t}\right)+(\alpha \beta) E_{t} \frac{\alpha}{1-\alpha} \pi_{3,1, t+1}+(\alpha \beta)\left(E_{t} \hat{P}_{3,1, t+1}-\hat{P}_{3,1, t}\right) \\
& -(1-\alpha \beta) \hat{P}_{3,1, t} \\
& =(1-\alpha \beta)\left(x_{t}+\hat{P}_{3, t}\right)+(\alpha \beta) E_{t} \frac{\alpha}{1-\alpha} \pi_{3,1, t+1} \\
& +(\alpha \beta) E_{t}\left(\pi_{3,1, t+1}\right)-(1-\alpha \beta) \hat{P}_{3,1, t} \\
& =(1-\alpha \beta)\left(x_{t}+\hat{P}_{3, t}\right)+(\alpha \beta) E_{t}\left[\frac{\alpha}{1-\alpha}+1\right] \pi_{3,1, t+1} \\
& -(1-\alpha \beta) \hat{P}_{3,1, t} \\
& =(1-\alpha \beta)\left(x_{t}+\hat{P}_{3, t}-\hat{P}_{3,1, t}\right)+(\alpha \beta) E_{t}\left[\frac{\alpha}{1-\alpha}+1\right] \pi_{3,1, t+1} \\
& \pi_{3,1, t}=\frac{(1-\alpha)(1-\alpha \beta)}{\alpha}\left(x_{t}+\hat{P}_{3, t}-\hat{P}_{3,1, t}\right)+(\alpha \beta) E_{t}\left[1+\frac{(1-\alpha)}{\alpha}\right] \pi_{3,1, t+1} \\
& x_{t}=\hat{m}_{1, t}-\hat{q}_{1,3, t} \\
& \pi_{3,1, t}=\frac{(1-\alpha)(1-\alpha \beta)}{\alpha}\left(\left(\hat{m}_{1, t}-\hat{q}_{1,3, t}\right)-\left(\hat{P}_{3,1, t}-\hat{P}_{3, t}\right)\right) \\
& +\beta E_{t} \pi_{3,1, t+1}
\end{aligned}
$$

The end result is

$$
\pi_{3,1, t}=\frac{(1-\alpha)(1-\alpha \beta)}{\alpha}\left(\left(\hat{m}_{1, t}-\hat{q}_{1,3, t}\right)+\left(\hat{P}_{3, t}-\hat{P}_{3,1, t}\right)\right)+\beta E_{t} \pi_{3,1, t+1} .
$$

By analogous arguments, we have in the general case,

$$
\pi_{i, j, t}=\frac{(1-\alpha)(1-\alpha \beta)}{\alpha}\left(\left(\hat{m}_{j, t}-\hat{q}_{i, j, t}\right)+\left(\hat{P}_{i, t}-\hat{P}_{i, j, t}\right)\right)+\beta E_{t} \pi_{i, j, t+1} .
$$

\section{Approximation for price levels}

$$
\begin{aligned}
\hat{P}_{i, t} & =d_{i, 1} \hat{P}_{i, 1, t}+d_{i, 2} \hat{P}_{i, 2, t}+d_{i, 3} \hat{P}_{i, 3, t} \\
& =d_{i, 1} \hat{P}_{i, 1, t}+d_{i, 2} \hat{P}_{i, 2, t}+\left(1-d_{i, 1}-d_{i, 2}\right) \hat{P}_{i, 3, t} \\
\hat{P}_{i, t}-\hat{P}_{i, 1, t} & =\left(d_{i, 1}-1\right) \hat{P}_{i, 1, t}+d_{i, 2}\left(\hat{P}_{i, 2, t}-\hat{P}_{i, 3, t}\right)+\left(1-d_{i, 1}\right) \hat{P}_{i, 3, t}
\end{aligned}
$$

It follows that 


$$
\begin{aligned}
\hat{P}_{i, t}-\hat{P}_{i, 1, t} & =d_{i, 2}\left(\hat{P}_{i, 2, t}-\hat{P}_{i, 3, t}\right)+\left(1-d_{i, 1}\right)\left(\hat{P}_{i, 3, t}-\hat{P}_{i, 1, t}\right) \\
\hat{P}_{i, t}-\hat{P}_{i, 2, t} & =d_{i, 1}\left(\hat{P}_{i, 1, t}-\hat{P}_{i, 3, t}\right)+\left(1-d_{i, 2}\right)\left(\hat{P}_{i, 3, t}-\hat{P}_{i, 2, t}\right) \\
\hat{P}_{i, t}-\hat{P}_{i, 3, t} & =d_{i, 1}\left(\hat{P}_{i, 1, t}-\hat{P}_{i, 3, t}\right)+d_{i, 2}\left(\hat{P}_{i, 2, t}-\hat{P}_{i, 3, t}\right)
\end{aligned}
$$

So for this particular case at hand,

$$
\left(\hat{P}_{3, t}-\hat{P}_{3,1, t}\right)=d_{3,2}\left(\hat{P}_{3,2, t}-\hat{P}_{3,3, t}\right)+\left(1-d_{3,1}\right)\left(\hat{P}_{3,3, t}-\hat{P}_{3,1, t}\right)
$$

Substitute into (74) to get,

$\pi_{3,1, t}=\frac{(1-\alpha)(1-\alpha \beta)}{\alpha}\left(\left(\hat{m}_{1, t}-\hat{q}_{1,3, t}\right)+\left(d_{3,2}\left(\hat{P}_{3,2, t}-\hat{P}_{3,3, t}\right)+\left(1-d_{3,1}\right)\left(\hat{P}_{3,3, t}-\hat{P}_{3,1, t}\right)\right)\right)+\beta E_{t} \pi_{3,1, t+1}$, and by definition, we also have

$$
\begin{aligned}
& \left(\hat{P}_{3,2, t}-\hat{P}_{3,3, t}\right)=\left(\hat{P}_{3,2, t-1}-\hat{P}_{3,3, t-1}\right)+\left(\pi_{3,2, t}-\pi_{3,3, t}\right) \\
& \left(\hat{P}_{3,3, t}-\hat{P}_{3,1, t}\right)=\left(\hat{P}_{3,3, t-1}-\hat{P}_{3,1, t-1}\right)+\left(\pi_{3,3, t}-\pi_{3,1, t}\right) .
\end{aligned}
$$

We'll have to write this out for each $i, j$ combination. Before we do this, we obtain the first-order approximation for the market clearing conditions, which we reproduce here for convenience.

$$
\begin{aligned}
Y_{1, t} & =C_{1,1, t}+C_{2,1, t}+C_{3,1, t} \\
Y_{2, t} & =C_{1,2, t}+C_{2,2, t}+C_{3,2, t} \\
Y_{1, t}+Y_{2, t}+Y_{3, t} & =C_{1, t}+C_{2, t}+C_{3, t} .
\end{aligned}
$$

We illustrate by approximating $Y_{1, t}$. Noting that the approximation of $C_{i, j, t}=d_{i, j}\left(\frac{P_{i, j, t}}{P_{i, t}}\right)^{-\mu} C_{i, t}$ is

$$
\hat{C}_{i, j, t}=\mu\left(\hat{P}_{i, t}-\hat{P}_{i, j, t}\right)+\hat{C}_{i, t}
$$

it follows that

$$
\hat{y}_{1, t}=\frac{C_{1,1}}{y_{1}} \hat{C}_{1,1, t}+\frac{C_{2,1}}{y_{1}} \hat{C}_{2,1, t}+\frac{C_{3,1}}{y_{1}} \hat{C}_{3,1, t} .
$$

In the steady state, $C_{1,1}=d_{1,1} C_{1}=d_{1,1} Y_{1} . \quad C_{2,1}=d_{2,1} C_{2}=d_{2,1} Y_{2}, C_{3,1}=d_{3,1} C_{3}=d_{3,1} Y_{3}$. This, together with (75) gives

$$
\begin{aligned}
\hat{Y}_{1, t}= & d_{1,1} \hat{C}_{1,1, t}+\left(\frac{d_{2,1} y_{2}}{y_{1}}\right) \hat{C}_{2,1, t}+\left(\frac{d_{3,1} y_{3}}{y_{1}}\right) \hat{C}_{3,1, t} \\
= & d_{1,1}\left(\mu\left(\hat{P}_{1, t}-\hat{P}_{1,1, t}\right)+\hat{C}_{1, t}\right)+\left(\frac{d_{2,1} Y_{2}}{Y_{1}}\right)\left(\mu\left(\hat{P}_{2, t}-\hat{P}_{2,1, t}\right)+\hat{C}_{2, t}\right) \\
& +\left(\frac{d_{3,1} Y_{3}}{Y_{1}}\right)\left(\mu\left(\hat{P}_{3, t}-\hat{P}_{3,1, t}\right)+\hat{C}_{3, t}\right) \\
= & \mu\left[d_{1,1}\left(\hat{P}_{1, t}-\hat{P}_{1,1, t}\right)+\left(\frac{d_{2,1} Y_{2}}{Y_{1}}\right)\left(\hat{P}_{2, t}-\hat{P}_{2,1, t}\right)+\left(\frac{d_{3,1} Y_{3}}{Y_{1}}\right)\left(\hat{P}_{3, t}-\hat{P}_{3,1, t}\right)\right] \\
& +d_{1,1} \hat{C}_{1, t}+\left(\frac{d_{2,1} Y_{2}}{Y_{1}}\right) \hat{C}_{2, t}+\left(\frac{d_{3,1} Y_{3}}{Y_{1}}\right) \hat{C}_{3, t}
\end{aligned}
$$


If the countries are equal in size such that in the steady state $Y_{1}=Y_{2}=Y_{3}$, we have

$$
\begin{aligned}
\hat{y}_{1, t}= & \mu\left(\psi_{1,1}\left(\hat{P}_{1, t}-\hat{P}_{1,1, t}\right)+d_{2,1}\left(\hat{P}_{2, t}-\hat{P}_{2,1, t}\right)+d_{3,1}\left(\hat{P}_{3, t}-\hat{P}_{3,1, t}\right)\right) \\
& +d_{1,1} \hat{C}_{1, t}+d_{2,1} \hat{C}_{2, t}+d_{3,1} \hat{C}_{3, t}
\end{aligned}
$$

Finally, we can use the decompositions

$$
\begin{aligned}
& \hat{P}_{1, t}-\hat{P}_{1,1, t}=d_{1,2}\left(\hat{P}_{1,2, t}-\hat{P}_{1,3, t}\right)+\left(1-d_{1,1}\right)\left(\hat{P}_{1,3, t}-\hat{P}_{1,1, t}\right) \\
& \hat{P}_{2, t}-\hat{P}_{2,1, t}=d_{2,2}\left(\hat{P}_{2,2, t}-\hat{P}_{2,3, t}\right)+\left(1-d_{2,1}\right)\left(\hat{P}_{2,3, t}-\hat{P}_{2,1, t}\right) \\
& \hat{P}_{3, t}-\hat{P}_{3,1, t}=d_{3,2}\left(\hat{P}_{3,2, t}-\hat{P}_{3,3, t}\right)+\left(1-d_{3,1}\right)\left(\hat{P}_{3,3, t}-\hat{P}_{3,1, t}\right)
\end{aligned}
$$

which come from

$$
\begin{aligned}
& \hat{P}_{1, t}=d_{1,1} \hat{P}_{1,1, t}+d_{1,2} \hat{P}_{1,2, t}+\left(1-d_{1,1}-d_{1,2}\right) \hat{P}_{1,3, t} \\
& \hat{P}_{2, t}=d_{2,1} \hat{P}_{2,1, t}+d_{2,2} \hat{P}_{2,2, t}+\left(1-d_{2,1}-d_{2,2}\right) \hat{P}_{2,3, t} \\
& \hat{P}_{3, t}=d_{3,1} \hat{P}_{3,1, t}+d_{3,2} \hat{P}_{3,2, t}+\left(1-d_{3,1}-d_{3,2}\right) \hat{P}_{3,3, t}
\end{aligned}
$$

in (77).

\section{The complete first-order approximated model}

We can now state the complete model.

$$
\begin{aligned}
\pi_{1,1, t}= & \frac{\left(1-\alpha_{1}\right)\left(1-\alpha_{1} \beta\right)}{\alpha_{1}}\left(\hat{m}_{1, t}+\left(\hat{P}_{1, t}-\hat{P}_{1,1, t}\right)\right)+\beta E_{t} \pi_{1,1, t+1} \\
\pi_{1,2, t}= & \frac{\left(1-\alpha_{1}\right)\left(1-\alpha_{1} \beta\right)}{\alpha_{1}}\left(\left(\hat{m}_{2, t}-\hat{q}_{2,1, t}\right)+\left(\hat{P}_{1, t}-\hat{P}_{1,2, t}\right)\right)+\beta E_{t} \pi_{1,2, t+1} \\
\pi_{1,3, t}= & \frac{\left(1-\alpha_{1}\right)\left(1-\alpha_{1} \beta\right)}{\alpha_{1}}\left(\left(\hat{m}_{3, t}-\hat{q}_{3,1, t}\right)+\left(\hat{P}_{1, t}-\hat{P}_{1,3, t}\right)\right)+\beta E_{t} \pi_{1,3, t+1} \\
\pi_{2,1, t}= & \frac{\left(1-\alpha_{2}\right)\left(1-\alpha_{2} \beta\right)}{\alpha_{2}}\left(\left(\hat{m}_{1, t}-\hat{q}_{1,2, t}\right)+\left(\hat{P}_{2, t}-\hat{P}_{2,1, t}\right)\right)+\beta E_{t} \pi_{2,1, t+1} \\
\pi_{2,2, t}= & \frac{\left(1-\alpha_{2}\right)\left(1-\alpha_{2} \beta\right)}{\alpha_{2}}\left(\hat{m}_{2, t}+\left(\hat{P}_{2, t}-\hat{P}_{2,2, t}\right)\right)+\beta E_{t} \pi_{2,2, t+1} \\
\pi_{2,3, t}= & \frac{\left(1-\alpha_{2}\right)\left(1-\alpha_{2} \beta\right)}{\alpha_{2}}\left(\left(\hat{m}_{3, t}-\hat{q}_{3,2, t}\right)+\left(\hat{P}_{2, t}-\hat{P}_{2,3, t}\right)\right)+\beta E_{t} \pi_{2,3, t+1} \\
\pi_{3,1, t}= & \frac{\left(1-\alpha_{3}\right)\left(1-\alpha_{3} \beta\right)}{\alpha_{3}}\left(\left(\hat{m}_{1, t}-\hat{q}_{1,3, t}\right)+\left(\hat{P}_{3, t}-\hat{P}_{3,1, t}\right)\right)+\beta E_{t} \pi_{3,1, t+1} \\
\pi_{3,2, t}= & \frac{\left(1-\alpha_{3}\right)\left(1-\alpha_{3} \beta\right)}{\alpha_{3}}\left(\left(\hat{m}_{2, t}-\hat{q}_{2,3, t}\right)+\left(\hat{P}_{3, t}-\hat{P}_{3,2, t}\right)\right)+\beta E_{t} \pi_{3,2, t+1} \\
\pi_{3,3, t}= & \frac{\left(1-\alpha_{3}\right)\left(1-\alpha_{3} \beta\right)}{\left.\hat{m}_{3, t}+\left(\hat{P}_{3, t}-\hat{P}_{3,3, t}\right)\right)+\beta E_{t} \pi_{3,3, t+1}}
\end{aligned}
$$




$$
\begin{aligned}
\hat{Y}_{1, t}= & \mu\left(d_{1,1}\left(\hat{P}_{1, t}-\hat{P}_{1,1, t}\right)+d_{2,1}\left(\hat{P}_{2, t}-\hat{P}_{2,1, t}\right)+d_{3,1}\left(\hat{P}_{3, t}-\hat{P}_{3,1, t}\right)\right) \\
& +d_{1,1} \hat{C}_{1, t}+d_{2,1} \hat{C}_{2, t}+d_{3,1} \hat{C}_{3, t} \\
\hat{Y}_{2, t}= & \mu\left(d_{1,2}\left(\hat{P}_{1, t}-\hat{P}_{1,2, t}\right)+d_{2,2}\left(\hat{P}_{2, t}-\hat{P}_{2,2, t}\right)+d_{3,2}\left(\hat{P}_{3, t}-\hat{P}_{3,2, t}\right)\right) \\
& +d_{1,2} \hat{C}_{1, t}+d_{2,2} \hat{C}_{2, t}+d_{3,2} \hat{C}_{3, t} \\
\hat{Y}_{3, t}= & \mu\left(d_{1,3}\left(\hat{P}_{1, t}-\hat{P}_{1,3, t}\right)+d_{2,3}\left(\hat{P}_{2, t}-\hat{P}_{2,3, t}\right)+d_{3,3}\left(\hat{P}_{3, t}-\hat{P}_{3,3, t}\right)\right) \\
& +d_{1,3} \hat{C}_{1, t}+d_{2,3} \hat{C}_{2, t}+d_{3,3} \hat{C}_{3, t}
\end{aligned}
$$

$$
\begin{aligned}
& \hat{Y}_{1, t}=\hat{A}_{1, t}+\hat{n}_{1, t} \\
& \hat{Y}_{2, t}=\hat{A}_{2, t}+\hat{n}_{2, t} \\
& \hat{Y}_{3, t}=\hat{A}_{3, t}+\hat{n}_{3, t} \\
& \hat{P}_{1, t}-\hat{P}_{1,1, t}=d_{1,2}\left(\hat{P}_{1,2, t}-\hat{P}_{1,3, t}\right)+\left(1-d_{1,1}\right)\left(\hat{P}_{1,3, t}-\hat{P}_{1,1, t}\right) \\
& \hat{P}_{2, t}-\hat{P}_{2,1, t}=d_{2,2}\left(\hat{P}_{2,2, t}-\hat{P}_{2,3, t}\right)+\left(1-d_{2,1}\right)\left(\hat{P}_{2,3, t}-\hat{P}_{2,1, t}\right) \\
& \hat{P}_{3, t}-\hat{P}_{3,1, t}=d_{3,2}\left(\hat{P}_{3,2, t}-\hat{P}_{3,3, t}\right)+\left(1-d_{3,1}\right)\left(\hat{P}_{3,3, t}-\hat{P}_{3,1, t}\right) \\
& \hat{P}_{1, t}-\hat{P}_{1,2, t}=d_{1,1}\left(\hat{P}_{1,1, t}-\hat{P}_{1,3, t}\right)+\left(d_{1,2}-1\right)\left(\hat{P}_{1,2, t}-\hat{P}_{1,3, t}\right) \\
& \hat{P}_{2, t}-\hat{P}_{2,2, t}=d_{2,1}\left(\hat{P}_{2,1, t}-\hat{P}_{2,3, t}\right)+\left(d_{2,2}-1\right)\left(\hat{P}_{2,2, t}-\hat{P}_{2,3, t}\right) \\
& \hat{P}_{3, t}-\hat{P}_{3,2, t}=d_{3,1}\left(\hat{P}_{3,1, t}-\hat{P}_{3,3, t}\right)+\left(d_{3,2}-1\right)\left(\hat{P}_{3,2, t}-\hat{P}_{3,3, t}\right) \\
& \hat{P}_{1, t,}-\hat{P}_{1,3, t}=d_{1,1}\left(\hat{P}_{1,1, t}-\hat{P}_{1,3, t}\right)+d_{1,2}\left(\hat{P}_{1,2, t}-\hat{P}_{1,3, t}\right) \\
& \hat{P}_{2, t}-\hat{P}_{2,3, t}=d_{2,1}\left(\hat{P}_{2,1, t}-\hat{P}_{2,3, t}\right)+d_{2,2}\left(\hat{P}_{2,2, t}-\hat{P}_{2,3, t}\right) \\
& \hat{P}_{3, t}-\hat{P}_{3,3, t}=d_{3,1}\left(\hat{P}_{3,1, t}-\hat{P}_{3,3, t}\right)+d_{3,2}\left(\hat{P}_{3,2, t}-\hat{P}_{3,3, t}\right) \\
& \hat{W}_{1, t}-\hat{P}_{1, t}=\gamma_{1} \hat{C}_{1, t}+\gamma_{2} \frac{n}{(1-n)} \hat{n}_{1, t} \\
& \hat{W}_{2, t}-\hat{P}_{2, t}=\gamma_{1} \hat{C}_{2, t}+\gamma_{2} \frac{n}{(1-n)} \hat{n}_{2, t} \\
& \hat{W}_{3, t}-\hat{P}_{3, t}=\gamma_{1} \hat{C}_{3, t}+\gamma_{2} \frac{n}{(1-n)} \hat{n}_{3, t}
\end{aligned}
$$




$$
\begin{aligned}
& \hat{M}_{1, t}-\hat{P}_{1, t}=\frac{\gamma_{1}}{(1+i) \gamma_{3}} \hat{C}_{1, t}-\frac{(1-i)}{(1+i) \gamma_{3}} \hat{\imath}_{1, t} \\
& \hat{M}_{2, t}-\hat{P}_{2, t}=\frac{\gamma_{1}}{(1+i) \gamma_{3}} \hat{C}_{2, t}-\frac{(1-i)}{(1+i) \gamma_{3}} \hat{\imath}_{2, t} \\
& \hat{M}_{3, t}-\hat{P}_{3, t}=\frac{\gamma_{1}}{(1+i) \gamma_{3}} \hat{C}_{3, t}-\frac{(1-i)}{(1+i) \gamma_{3}} \hat{\imath}_{3, t}
\end{aligned}
$$

$$
\begin{aligned}
& \hat{C}_{1, t}=E_{t}\left(\hat{C}_{1, t+1}-\frac{1}{\gamma_{1}}\left(\hat{\imath}_{1, t}-\hat{\pi}_{1, t+1}\right)\right) \\
& \hat{C}_{2, t}=E_{t}\left(\hat{C}_{2, t+1}-\frac{1}{\gamma_{1}}\left(\hat{\imath}_{2, t}-\hat{\pi}_{2, t+1}\right)\right) \\
& \hat{C}_{3, t}=E_{t}\left(\hat{C}_{3, t+1}-\frac{1}{\gamma_{1}}\left(\hat{\imath}_{3, t}-\hat{\pi}_{3, t+1}\right)\right)
\end{aligned}
$$

$$
\begin{aligned}
& \hat{q}_{1,2, t}=-\gamma_{1}\left(\hat{C}_{2, t}-\hat{C}_{1, t}\right) \\
& \hat{q}_{1,3, t}=-\gamma_{1}\left(\hat{C}_{3, t}-\hat{C}_{1, t}\right) \\
& \hat{q}_{2,3, t}=-\gamma_{1}\left(\hat{C}_{3, t}-\hat{C}_{2, t}\right)
\end{aligned}
$$




\section{Monetary Policy Rule Estimates}

Table 7: Cross-Rate Management.

Estimates of equation (33). Newey-West t-ratios in parentheses

\begin{tabular}{|c|c|c|c|c|c|}
\hline Country & Cross rate & $\rho$ & $\lambda$ & $\phi$ & $\sigma$ \\
\hline \multirow[t]{6}{*}{ Brazil } & euro & $0.791^{* *}$ & -0.181 & 0.330 & $0.301^{* *}$ \\
\hline & & $(13.552)$ & $(-0.383)$ & $(0.900)$ & $(3.664)$ \\
\hline & $\mathrm{SF}$ & $0.766^{* *}$ & $-1.432^{* *}$ & $0.595^{* *}$ & $0.359^{* *}$ \\
\hline & & $(15.753)$ & $(-2.043)$ & $(2.477)$ & $(4.573)$ \\
\hline & yen & $0.736^{* *}$ & $-1.219^{*}$ & $0.467^{*}$ & $0.267^{* *}$ \\
\hline & & (11.129) & $(-1.933)$ & (1.684) & $(4.780)$ \\
\hline \multirow[t]{2}{*}{ Canada } & euro & $0.733^{* *}$ & -0.349 & $1.576^{* *}$ & $0.084^{*}$ \\
\hline & & $(8.930)$ & $(-1.289)$ & $(7.944)$ & $(1.849)$ \\
\hline \multirow[t]{2}{*}{ Denmark } & euro & $0.769^{* *}$ & -0.676 & $0.269^{* *}$ & $0.769^{* *}$ \\
\hline & & (11.008) & $(-1.569)$ & $(5.574)$ & $(4.616)$ \\
\hline \multirow[t]{2}{*}{ UK } & yen & $0.810^{* *}$ & $0.196^{*}$ & -0.231 & $0.047^{*}$ \\
\hline & & $(8.975)$ & $(1.854)$ & $(-0.676)$ & $(1.844)$ \\
\hline \multirow[t]{2}{*}{ Indonesia } & yen & $0.695^{* *}$ & 0.087 & - & $0.072^{* *}$ \\
\hline & & $(28.259)$ & $(0.669)$ & - & $(2.320)$ \\
\hline \multirow[t]{2}{*}{ Japan } & euro & $0.730 * *$ & 0.034 & 0.000 & $0.016^{* *}$ \\
\hline & & $(7.857)$ & $(0.266)$ & $(0.028)$ & $(3.274)$ \\
\hline \multirow[t]{2}{*}{ Norway } & yen & $0.880^{* *}$ & 0.077 & - & $0.013^{*}$ \\
\hline & & (13.324) & $(0.234)$ & - & $(1.885)$ \\
\hline \multirow[t]{4}{*}{ Philippines } & euro & $0.794^{* *}$ & -0.386 & - & $0.103^{* *}$ \\
\hline & & $(25.674)$ & $(-1.606)$ & - & $(3.260)$ \\
\hline & yen & $0.818^{* *}$ & 0.044 & - & $0.069^{* *}$ \\
\hline & & $(23.397)$ & $(0.302)$ & - & $(2.399)$ \\
\hline \multirow[t]{2}{*}{ Singapore } & yen & $0.947^{* *}$ & -0.012 & - & 0.160 \\
\hline & & $(18.500)$ & $(-0.019)$ & - & $(1.234)$ \\
\hline \multirow[t]{2}{*}{ Switzerland } & euro & $0.606^{* *}$ & $0.227^{* *}$ & $-0.231^{*}$ & $0.065^{* *}$ \\
\hline & & $(9.396)$ & $(6.605)$ & $(-1.849)$ & $(3.141)$ \\
\hline \multirow[t]{2}{*}{ Thailand } & euro & $0.654^{* *}$ & -0.220 & - & 0.124 \\
\hline & & $(2.862)$ & $(-1.195)$ & - & $(1.531)$ \\
\hline
\end{tabular}

Notes: $*(* *)$ indicates significance at the $10(5)$ percent level. 